\title{
Unemployment, Growth and Welfare Effects of Labor Market Reforms
}

\author{
Pierre-Richard Agénor* and King Yoong Lim** \\ First complete draft: July 25, 2016 \\ Final version: August 3, 2018
}

\begin{abstract}
The effects of labor market reforms are studied in an innovation-driven model of endogenous growth with a heterogeneous labor force, labor market rigidities, and structural unemployment. The model is calibrated for a stylized middle-income economy in Latin America and used to perform a range of experiments, including both individual labor market reforms (cuts in the minimum wage and unemployment benefit rates) and composite reform programs involving additional measures. The results show that individual reforms may generate conflicting effects on growth and welfare in the long run, even in the presence of positive policy externalities. A reduction in training costs may also create an oversupply of qualified labor and higher unemployment in the long run. Public investment in infrastructure, partly through its effects on innovation, can help to mitigate this oversupply problem.
\end{abstract}

JEL Classification Numbers: E24, J21, O41

${ }^{*}$ School of Social Sciences, University of Manchester, and ${ }^{* *}$ Nottingham Business School. We are grateful to participants at various seminars and the Royal Economic Society Annual Conference in Bristol, as well as the Editors and an anonymous referee, for helpful comments and discussions. 


\section{Introduction}

The impact of labor market reforms on unemployment and economic growth has been the focus of a large theoretical and empirical literature. From an analytical perspective, important issues in that context are the modeling of the production structure and the causes of mismatches between supply and demand in the labor market. Accounting for innovation activities for instance is critical to study the role of human capital accumulation, knowledge externalities, and the distribution of skills as sources of growth and employment; and modeling labor market rigidities is essential to explain unemployment. The dominant literature on labor market rigidities in recent years has been based on the Diamond-MortensenPissarides search framework (see, for example, Zagler (2009) and Cacciatore and Fiori (2016)). While search frictions have contributed to much better policy management of cyclical unemployment in the short-run, it is technically not a structural institutional issue. Structural rigidities can be referred to government legislation on minimum wages, mandated firing costs, unemployment benefits, collective bargaining, and Shapiro-Stiglitz style efficiency wages. A large number of studies focusing on one or two of these rigidities have been made in recent years, which include Varga et al. (2014), Bhattacharyya and Gupta (2015) and Chang and Hung (2016) on the collective bargaining front, and Bucci et al. (2003), Meckl (2004), Parello (2011), and Zagler (2011) on the efficiency wage front. ${ }^{1}$ A key result from the literature is that the relationship between growth and unemployment may be weak, both on impact and in the long run.

However, the existing theoretical literature suffers from three major shortcomings. First, except for a few contributions - such as Cacciatore and Fiori (2016), albeit in a business cycle setting - most of the literature neglects dynamic trade-offs that may be associated with labor market reforms, that is, the possibility of conflicting effects in the short and the longer run in terms of their impact on either unemployment or growth. Second, almost none of the existing models considers the supply side of the labor market. In particular, the distribution of the labor force across levels of education, and how it changes over time, are seldom explicitly analyzed. ${ }^{2}$ This creates a major difficulty in terms of understanding how

\footnotetext{
${ }^{1}$ Some of these contributions also account for the existence of an innovation sector, albeit (as discussed next) in a partial manner.

${ }^{2}$ Some models introduce a work-leisure trade-off into workers' utility functions (thereby accounting for the intensive margin of labor supply), but the labor force distribution across skills (the extensive margin) is
} 
the labor market adjusts in response to shocks, how it interacts with the process of economic growth, and how public policy can affect unemployment and its composition. Third, only a few contributions (including again Cacciatore and Fiori (2016)) study the impact of labor market reforms on welfare and the possibility that growth and welfare effects may move in opposite directions. Doing so is important because it may help to understand resistance to reform. Finally, there have been few attempts to assess quantitatively - in terms of unemployment, growth, or welfare - the benefits of a simultaneous implementation of labor market reforms, compared to a piecemeal approach, and the scope for exploiting policy externalities to mitigate the welfare cost of reforms. This matters because the impact of a specific policy may depend on whether other policies are implemented at the same time. Ignoring policy externalities is a potential source of bias.

The purpose of this paper is to address all of these issues, using an overlapping generations (OLG) endogenous growth model with a heterogeneous labor force, final good and innovation sectors, labor market rigidities, and structural unemployment. To model wage formation in final good production, where activity involves more routine tasks and effort is fully observable, trade unions are introduced; but to model wage formation in the innovation sector, an efficiency wage specification is adopted. This approach, as argued elsewhere in the literature, is better suited than standard search models of the Mortensen-Pissarides type to understand the link between wages and productivity in innovation activities over the long-run, notably in a developing economy context. Indeed, in these activities, firms cannot monitor researchers' effort perfectly; the key issue for an employer is thus to mitigate incentives to shirk and to encourage creativity. A natural approach is thus to use an efficiency wage framework, in this case linking effort and wages. As a result, persistent uncompetitive wage differentials for highly-skilled workers may emerge across sectors.

While we are able to solve for the balanced growth path, the complexity of our model precludes a full analytical characterization of its dynamic properties. We therefore calibrate it to perform an extensive range of quantitative simulations for a group of middle-income Latin American countries that are characterized by a range of labor market rigidities (including high minimum wages and active trade unions), and have recorded high structural unemployment rates in recent years. Indeed, long-term structural unemployment has been but these studies also fail to account for the heterogeneous distribution of skills in the labor force. 
a long standing issue in many economies in Latin America. While the average headline unemployment rate for the five main upper-middle income economies (Argentina, Brazil, Chile, Colombia, and Peru) in recent years has receded from a high of 13.3 percent in 2000 to about 10.8 percent in 2017 , structural unemployment remains a key policy concerndespite decades of efforts to promote ambitious labor market reforms in the region. At the end of 2017, 26.4 million people were unemployed in Latin America and the Caribbean as a whole, some 2 million more than just the year before (International Labour Organization $(2017))^{3}$

We assess the impact of labor market reforms not only on unemployment, growth, and welfare, but also on the misallocation of talent, a situation where individuals with abilities that are high enough to operate in the innovation sector end up instead performing routine production tasks. In an innovation-driven economy this is costly for society as a whole, even though these individuals are (like everybody else) utility maximizers.

In addition to evaluating the effects of single policy experiments, we consider composite programs and examine to what extent policy externalities mitigate the adverse effects of individual reforms. We also consider the cases where composite reform programs are combined with skills expansion, as well as an increase in public investment in infrastructure. Such investments have been advocated in the aftermath of the global financial crisis - not only as a short-term Keynesian response because of their demand-side effects, but also as a fundamental step to improve productivity because of their supply-side effects (see for instance LSE Growth Commission (2013) and International Monetary Fund (2016)).

To preview our results, we find that labor market reforms entail a two-way causality between growth and unemployment: growth tends to lower unemployment, through its impact on labor demand; but unemployment may lower growth because it reduces (through its wage signalling effects) incentives to acquire skills and constrains the ability to expand innovation activities - a key engine of growth. Individual labor market reforms may generate a weak correlation between growth and unemployment, as predicted in a number of existing studies; in addition, they may have conflicting effects on growth and welfare in the long run. To some extent, this trade-off can be tempered by exploiting policy externali-

\footnotetext{
${ }^{3}$ The only other region where unemployment rates are higher is the Middle East and North Africa, where religious and cultural factors play a significant role. In other developing regions open unemployment rates are low, either because employment rates are high (Asia and the Pacific) or because unemployment is mostly disguised (Sub-Saharan Africa).
} 
ties. But to avoid creating an oversupply of specialized workers, governments must refrain from adopting policies such as drastic reductions in effective tuition fees, which would only contribute to an absorption problem and potentially large numbers of unemployment graduates.

In addition, public investment in infrastructure may help to boost employment and mitigate the oversupply problem, partly by promoting innovation activities. Finally, a comparison of the sum of the long-run effects in terms of growth, unemployment and welfare of each individual policy in a composite program with those associated with the same composite program suggests that, if unemployment or social welfare matters more than growth to policymakers, comprehensive reform programs may generate negative externalities. With limited political capital, overly ambitious labor market reform programs may therefore be costly and ineffective.

The remainder of the paper is organized as follows. Section 2 presents the model. Section 3 defines the balanced growth equilibrium and Section 4 characterizes its properties. Section 5 describes the calibration of the model for Latin America. Section 6 considers a variety of individual labor market policies (including a reduction in the minimum wage and a reduction in unemployment benefit rates), as well as a policy aimed at promoting the acquisition of skills. Section 7 considers composite reform programs involving a combination of these policies, with and without increases in public investment on infrastructure. ${ }^{4}$ The final section provides some concluding remarks. ${ }^{5}$

\section{The Model}

The economy that we consider is populated by individuals with different innate abilities, who live for two periods, adulthood and old age. Population is constant at $\bar{N}$. Each individual is endowed with one unit of time in each period of life. In old age, time is allocated entirely to leisure. There are four production sectors: a manufacturing sector, which produces a homogeneous final good with routine tasks, an intermediate goods sector, an innovation sector, which creates designs used for producing intermediate goods, and an

\footnotetext{
${ }^{4}$ Appendix $\mathrm{C}$ provides a sensivitity analysis with respect to all experiments. The results are quantitatively and qualitatively robust to a significant range of parameter changes.

${ }^{5}$ In the working paper version of this article, we also perform all of these experiments with a group of high-income European countries and provide a systematic comparison of the results.
} 
education sector, which allows individuals to acquire advanced training. The final good is produced by combining both private and public inputs, and is used for consumption, private and public investment, and the production of intermediate goods. The public input consists of infrastructure and is provided free of direct charges. However, it is subject to congestion. Production in the innovation sector combines public and private inputs as well, but workers' effort is not observable.

Firms in the final good and innovation sectors are perfectly competitive whereas those in the intermediate good sector are monopolistically competitive, producing (as in Romer (1990)) differentiated varieties of goods. The total number of blueprints existing at a certain point in time coincides with the number of intermediate input varieties available, and represents the stock of (nonrival) knowledge.

Two categories of labor are available, untrained (with only basic education) and specialized (with advanced education). Workers are born untrained and must decide at the beginning of adulthood whether or not to become specialized. Acquiring advanced education requires both time and pecuniary costs. While all specialized workers can work in the final good sector, only those with the highest ability can work in the innovation sector, as for instance in Böhm et al. (2015). Rigidities prevail in all segments of the labor market and unemployment emerges in equilibrium. ${ }^{6}$

Figure 1 summarizes the production structure and the sectoral distribution of labor. Although it does not show (for clarity) how employment and unemployment probabilities are determined, it illustrates fairly well how labor market rigidities affect wage formation and unemployment, and the feedback effect of unemployment (through its impact on compensation for the unemployed) on expected wages and the decision to acquire advanced training.

\section{$2.1 \quad$ Individuals}

Individuals have identical preferences but are born with different abilities, indexed by $a$. Ability follows a continuous distribution with density function $f(a)$ and cumulative distri-

\footnotetext{
${ }^{6}$ We do not model employment protection legislation and therefore do not analyze their impact on structural unemployment and growth. This is in line with the results of Duval and Furceri (2018), which show that these measures do not have a medium-term impact on output and employment, only cyclical effects.
} 
bution function $F(a)$, with support $(0,1)$. For tractability, $a$ is assumed to be uniformly distributed on its support. Each individual maximizes utility and decides whether to engage in market work as an untrained worker or (after training) as a specialized worker.

Specifically, an adult with ability $a$ can enter the labor force at the beginning of period $t$ as an untrained worker and earn the wage $w_{t}^{U}$, which is independent of the worker's ability. Alternatively, the individual may choose to first spend a fraction $\varepsilon \in(0,1)$ of his/her time endowment at the beginning of adulthood in higher education, incur a cost $t c_{t}>0$, and then enter the labor force for the remainder of the period as a specialized worker, earning either the wage $w_{t}^{S Y}$ if employed in the final good sector, or $w_{t}^{S R}$ if employed in the innovation sector. During training, workers earn no income. All individuals can either be employed (superscript $E$ ) or unemployed (superscript $L$ ). If employed, an untrained individual can work only in the final good sector. All specialized individuals can work in that sector as well, but only those with the highest level of ability, $a>a^{R}$, can potentially work in the innovation sector. The threshold ability level $a^{R}$ is taken to be constant, consistent with the assumption that, for any given population, the spread of individuals along the ability continuum is largely determined by nature. ${ }^{7}$ If unemployed, individuals earn an unemployment benefit, $b_{t}^{h}, h=U, S$, which is not taxable.

Let $c_{t \mid t+n}^{h, j}$ denote consumption at period $t+n$ of an individual $h=U, S Y, S R$, either employed or unemployed, $j=E, L$, born at the beginning of period $t$, with $n=0,1$. The individual's discounted utility function is given by

$$
V_{t}^{h, j}=\eta_{C} \ln c_{t \mid t}^{h, j}+\frac{\ln c_{t \mid t+1}^{h, j}}{1+\rho}, h=U, S Y, S R, \quad j=E, L
$$

where $\rho, \eta_{C}>0$ are the common discount rate and preference parameter for current consumption, respectively. ${ }^{8}$

The period-specific budget constraints are given by

$$
\begin{gathered}
c_{t \mid t}^{U, j}+s_{t}^{U j}=\left\{\begin{array}{ll}
(1-\tau) w_{t}^{U} & \text { if } j=Y \\
b_{t}^{U} & \text { if } j=L
\end{array},\right. \\
c_{t \mid t}^{h, j}+s_{t}^{h}= \begin{cases}(1-\tau)\left[(1-\varepsilon) w_{t}^{h}-t c_{t}\right] & \text { if } j=E, h=S Y, S R \\
(1-\varepsilon) b_{t}^{S}-t c_{t} & \text { if } j=L\end{cases}
\end{gathered}
$$

\footnotetext{
${ }^{7}$ Hypotheses such as the Flynn effect in the psychological science literature do suggest that IQ scores tend to improve as the share of the skilled population grows (see Flynn (2007)). However, this remains a contentious subject of research and in the absence of conclusive evidence we treat $a^{R}$ as fixed.

${ }^{8}$ Because leisure does not enter the utility function, the opportunity cost of unemployment is simply the wage foregone.
} 


$$
c_{t \mid t+1}^{h, j}=\left(1+r_{t+1}\right) s_{t}^{h}, \quad h=U, S Y, S R, \quad j=E, L
$$

where $s_{t}^{h, j}$ is savings, $1+r_{t+1}$ the gross rate of return between periods $t$ and $t+1$, and $\tau \in(0,1)$ the tax rate.

An individual finds it optimal to train if and only if his/her expected earnings as a specialized worker, adjusted for the time and pecuniary costs of training, exceeds the expected earnings of an untrained worker:

$$
(1-\varepsilon)\left\{(1-\tau)\left[\zeta_{t}^{S Y} w_{t}^{S Y}+\zeta_{t}^{S R} w_{t}^{S R}\right]+\zeta_{t}^{S L} b_{t}^{S}\right\}-t c_{t} \geq\left(1-\zeta_{t}^{U L}\right)(1-\tau) w_{t}^{U}+\zeta_{t}^{U L} b_{t}^{U}
$$

where the going wage, or the unemployment benefit, is weighted by the respective probability of being either employed or unemployed, $\zeta_{t}^{h} \in(0,1)$, for $h=S Y, S R, S L, U L .^{9}$ In specifying (5), we assume for simplicity that an individual knows if his/her ability is above or below the threshold $a^{C}$ and can therefore decide whether to acquire specialized skills or not at the beginning of adulthood, but finds out whether his/her ability is at or above $a^{R}>a^{C}$ only after undergoing training. Put differently, this specification captures the idea that an individual discovers whether he/she is "super smart" only upon college graduation - a sensible assumption in practice. ${ }^{10}$

The training cost is proportional to the expected specialized wage when employed and varies inversely with the individual's ability, which determines how fast (or how well) he or she can learn:

$$
t c_{t}=\mu(1-\varepsilon)\left(\zeta_{t}^{S Y} w_{t}^{S Y}+\zeta_{t}^{S R} w_{t}^{S R}\right) / a^{\chi}
$$

with $\mu, \chi \in(0,1)$. The assumption on the productivity parameter $\chi$ ensures that the effect of ability on training costs is subject to diminishing returns.

As shown in Appendix A, the threshold level of ability $a_{t}^{C}$ such that all individuals with

\footnotetext{
${ }^{9}$ Equation (5) is assumed to hold as a strict inequality for the individual with the highest ability, that is, $a=1$, otherwise nobody would choose to become specialized. In principle, given that agents have concave utility, they should care not only about the expected value of earnings but also about risk. The decision to acquire skills should thus depend on expected utility under alternative occupations, as in Agénor and Alpaslan (2014) for instance. However, in the present setting the resulting condition cannot be solved explicitly for the threshold level of ability.

${ }^{10}$ Without this assumption two separate conditions, one for those with $a>a^{R}$ (which would take the form shown in (5), given that these individuals can work anywhere) and one for those with $a<a^{R}$ (which would exclude the wage in the innovation sector in calculating the expected specialized wage) would be required. This would complicate significantly the analysis, without adding much additional insight.
} 
ability higher than $a_{t}^{C}$ choose to undergo training is given by

$$
a_{t}^{C}=\mu^{1 / \chi}\left\{1-\frac{\left(1-\zeta_{t}^{U L}\right)(1-\tau) w_{t}^{U}+\zeta_{t}^{U L} b_{t}^{U}-(1-\varepsilon) \zeta_{t}^{S L} b_{t}^{S}}{(1-\varepsilon)(1-\tau)\left(\zeta_{t}^{S Y} w_{t}^{S Y}+\zeta_{t}^{S R} w_{t}^{S R}\right)}\right\}^{-1 / \chi}
$$

This equation plays an important role in understanding the dynamics of the labor market; it shows that labor market outcomes (which are partly influenced by public policy) have a direct impact on the decision to acquire training, through their effect on expected, rather than actual, wages.

The productivity of untrained workers is constant regardless of ability and is normalized to unity. Given (7), the raw supply of untrained labor, $N_{t}^{U}$, is equal to the number of individuals in the population who choose not to undergo training:

$$
N_{t}^{U}=\bar{N} \int_{0}^{a_{t}^{C}} f(a) d a=a_{t}^{C} \bar{N}
$$

The raw supply of specialized workers with ability $a \in\left(a_{t}^{C}, a^{R}\right)$ is $\bar{N} \int_{a_{t}^{C}}^{a^{R}} f(a) d a=$ $\left(a^{R}-a_{t}^{C}\right) \bar{N}$. However, the average productivity of these workers equals $\left(a_{t}^{C}+a^{R}\right) / 2$; thus, the effective supply of specialized labor with $a \in\left(a_{t}^{C}, a^{R}\right)$ can be defined as

$$
\frac{\left(a^{R}-a_{t}^{C}\right)\left(a_{t}^{C}+a^{R}\right)}{2} \bar{N}=\frac{\left(a^{R}\right)^{2}-\left(a_{t}^{C}\right)^{2}}{2} \bar{N} .
$$

As noted earlier, among specialized workers, only those with ability $a \in\left(a^{R}, 1\right)$ can operate in the innovation sector; thus, the (effective) supply of labor to that segment of the market, $N_{t}^{R}$, is

$$
N_{t}^{R}=\frac{\left(1-a^{R}\right)\left(a^{R}+1\right)}{2} \bar{N}=\frac{1-\left(a^{R}\right)^{2}}{2} \bar{N} .
$$

Adding (9) and (10), the total (effective) supply of specialized workers, $N_{t}^{S}$, is

$$
N_{t}^{S}=\frac{1-\left(a_{t}^{C}\right)^{2}}{2} \bar{N}
$$

However, workers with the highest ability are also able to work in the final good sector, at the same wage as other specialized workers there. Assuming that all workers with ability greater than $a^{R}$ seek employment in innovation activities first, the supply of specialized labor to manufacturing is not given by $N_{t}^{S}-N_{t}^{R}$, but rather by $N_{t}^{S}-N_{t}^{S R}$, where $N_{t}^{S R} \leq N_{t}^{R}$ is the actual (demand-determined) level of employment in the innovation sector. Thus, to the extent that $N_{t}^{R}>N_{t}^{S R}$, there is misallocation of talent, in the sense that individuals 
with abilities that are high enough to operate in the innovation sector may end up performing routine tasks in manufacturing - at a cost to society in terms of growth and welfare. In our numerical experiments we measure talent misallocation by the share of "overqualified" workers in the final good sector, defined as $\max \left[0,\left(N_{t}^{R}-N_{t}^{S R}\right) / N_{t}^{S Y}\right]$, where $N_{t}^{S Y}$ is actual employment in that sector.

\subsection{Final Good}

Final good production by firm $i, Y_{t}^{i}$, requires the use of specialized labor, $N_{i, t}^{S Y}$, untrained labor, $N_{i, t}^{U Y}$, private capital, $K_{i, t}^{P}$, aggregate public capital, $K_{t}^{G}$, and the combination of intermediate inputs, $x_{i, s, t}$, with $s \in\left(0, M_{t}\right)$.

The production function is specified as

$$
Y_{t}^{i}=\left[\frac{K_{t}^{G}}{\left(K_{t}^{P}\right)^{\zeta} \bar{N} \zeta_{N}}\right]^{\omega}\left[(1-\varepsilon) N_{i, t}^{S Y}\right]^{\beta^{S}}\left(N_{i, t}^{U Y}\right)^{\beta^{U}}\left(K_{i, t}^{P}\right)^{\alpha}\left[\int_{0}^{M_{t}} x_{i, s, t}^{\eta} d s\right]^{\gamma / \eta},
$$

where $\beta^{S}, \beta^{U}, \alpha, \gamma \in(0,1), \omega>0, \zeta_{K}, \zeta_{N}>0, \gamma=1-\left(\beta^{S}+\beta^{U}\right)-\alpha, \eta \in(0,1)$ and $1 /(1-\eta)>1$ is (the absolute value of) the price elasticity of demand for each intermediate good, and $K_{t}^{P}=\int_{0}^{1} K_{i, t}^{P}$ aggregate private capital. Constant returns therefore prevail with respect to private inputs, and public capital is subject to congestion, measured by aggregate private capital and population.

Firm $i$ 's profits are defined as

$$
\Pi_{i, t}^{Y}=Y_{t}^{i}-\int_{0}^{M_{t}} P_{t}^{s} x_{i, s, t} d s-\left(1+\varsigma_{t}\right)\left[w_{t}^{S Y}(1-\varepsilon) N_{i, t}^{S Y}+w_{t}^{U} N_{i, t}^{U Y}\right]-\left(r_{t}+\delta^{P}\right) K_{i, t}^{P},
$$

where $\delta^{P} \in(0,1)$ is the depreciation rate and $\varsigma_{t}>0$ is the firm's contribution rate to the unemployment insurance scheme, based on its total wage bill.

Each firm maximizes profits subject to (12) with respect to labor, private capital, and quantities of intermediate goods $x_{i, s, t}, \forall s$, taking factor prices and $M_{t}$ as given. This yields, in standard fashion,

$$
\begin{gathered}
w_{t}^{S Y}=\left(\frac{\beta^{S}}{1+\varsigma_{t}}\right) \frac{Y_{i, t}}{(1-\varepsilon) N_{i, t}^{S Y}}, \quad w_{t}^{U}=\left(\frac{\beta^{U}}{1+\varsigma_{t}}\right) \frac{Y_{i, t}}{N_{i, t}^{U Y}} \\
r_{t}=\alpha\left(Y_{i, t} / K_{i, t}^{P}\right)-\delta^{P} \\
x_{i, s, t}=\left(\frac{\gamma Z_{i, t}}{P_{t}^{s}}\right)^{1 /(1-\eta)}, \quad s=1, \ldots M_{t}, \\
Z_{i, t}=Y_{i, t} / \int_{0}^{M_{t}}\left(x_{i, s, t}\right)^{\eta} d s .
\end{gathered}
$$




\subsection{Intermediate Goods}

As in Romer (1990), intermediate goods firms produce inputs based on blueprints produced by the innovation sector. Each firm produces one, and only one, horizontally-differentiated good, using the same technology used to produce the final good. Production of each unit of intermediate goods costs one unit of final output.

Each producer must purchase a patented design from the innovation sector. Once the patent fee $Q_{t}$ is paid, each producer sets its price to maximize profits, given the perceived demand function for its good (15), which determines marginal revenue. Under a symmetric equilibrium, profits are given by $\Pi_{t}^{I}=\left(P_{t}-1\right) x_{t}$ or, using (15) and (16), $\Pi_{t}^{I}=\left(P_{t}-\right.$ 1) $\left[\gamma Y_{t} / P_{t} M_{t} x_{t}^{\eta}\right]^{1 /(1-\eta)}$. In standard fashion, the solution yields the optimal price as

$$
P_{t}^{s}=\frac{1}{\eta} \cdot \forall s=1, \ldots M_{t}
$$

Using (15), the quantity demanded at this price is $x_{s, t}=\left(\gamma \eta Z_{t}\right)^{1 /(1-\eta)}, \forall s$, that is, noting that under symmetry $\int_{0}^{M_{t}} x_{s, t}^{\eta} d s=M_{t} x_{t}^{\eta}$,

$$
x_{t}=\gamma \eta\left(\frac{Y_{t}}{M_{t}}\right)
$$

with maximum profit given by

$$
\Pi_{t}^{I}=(1-\eta) \gamma\left(\frac{Y_{t}}{M_{t}}\right)
$$

Intermediate-input producing firms last only one period, and patents are auctioned off randomly to a new group of firms in each period. Thus, each firm holds a patent only for the period during which it is bought, implying monopoly profits during that period only; yet patents last forever. ${ }^{11}$ By arbitrage, therefore,

$$
Q_{t}=\Pi_{t}^{I}
$$

\subsection{Innovation Sector}

Firms in the innovation sector use only high-ability specialized labor, in quantity $(1-\varepsilon) N_{t}^{S R}$. There is no aggregate uncertainty and the production technology is

$$
M_{t+1}-M_{t}=A_{t}^{R}\left[\frac{e_{t}^{R}(1-\varepsilon) N_{t}^{S R}}{\bar{N}}\right]^{\lambda}
$$

\footnotetext{
${ }^{11}$ This assumption simplifies significantly the analysis; see Agénor and Canuto (2015b) for a discussion.
} 
where $e_{t}^{R}$ is the level of effort and $A_{t}^{R}$ productivity, which depends on access to public infrastructure and, consistent with the standing-on-shoulder effect (see Jones (2005)), the stock of knowledge:

$$
A_{t}^{R}=\left(k_{t}^{G}\right)^{\phi_{1}^{R}} M_{t}
$$

with $k_{t}^{G}=K_{t}^{G} / K_{t}^{P}$ and $\phi_{1}^{R}>0$. Thus, in terms of efficiency units of labor, effort and workers are perfect substitutes. Because of duplication effects there are diminishing marginal returns to labor, so that $\lambda \in(0,1) .{ }^{12}$ Access to public capital is subject to (proportional) congestion, measured (for simplicity) by private capital only. In addition, to eliminate scale effects, as in Dinopoulos and Segerstrom (1999) innovation difficulty is measured in terms of population size.

Effort is modeled following the simple specification developed in Agénor and Aizenman (1999). In deciding how much effort to provide at $t$, researchers evaluate a period utility function, $U^{R}\left(w_{t}^{S R}, 1-e_{t}^{R}\right)$, which depends on the wage earned, $w_{t}^{S R}$, and the disutility of effort, $1-e_{t}^{R}$ :

$$
\left.U^{R}\left[w_{t}^{S R}, 1-e_{t}^{R}\right]=\ln \left[(1-\tau) w_{t}^{S R}\right)^{\delta_{R}}\left(1-e_{t}^{R}\right)^{1-\delta_{R}}\right],
$$

where $\delta_{R} \in(0,1)$. Let $\pi$ denote the probability that a researcher is caught shirking, in which case he is fired and ends up being either employed in manufacturing, at the going wage $w_{t}^{S Y}$, or unemployed, collecting the benefit $b_{t}^{S}$. In line with the standard ShapiroStiglitz shirking model, we assume that $\pi$ is related one-to-one with the intensity with which firms in the innovation sector choose to monitor their workers.

The level of effort provided is either $e_{t}^{R}$, when employed and not shirking, or the minimum $e_{m}^{R} \in(0,1)$, when shirking while employed. The optimal level of effort is such that the utility derived from working without shirking (as given by (23)) is at least equal to the expected utility of shirking:

$$
\begin{gathered}
U^{R}\left(w_{t}^{S R}, 1-e_{t}^{R}\right) \geq \pi \ln \left[\left(\zeta_{t}^{S Y}(1-\tau) w_{t}^{S Y}+\zeta_{t}^{S L} b_{t}^{S}\right)^{\delta_{R}}\left(1-e_{m}^{R}\right)^{1-\delta_{R}}\right] \\
+(1-\pi) \ln \left[\left((1-\tau) w_{t}^{S R}\right)^{\delta_{R}}\left(1-e_{m}^{R}\right)^{1-\delta_{R}}\right]
\end{gathered}
$$

where the latter is defined as a weighted average of the expected income earned if caught shirking and fired with probability $\pi$ (either working at the alternative wage $w_{t}^{S Y}$, with probability $\zeta_{t}^{S Y}$, or unemployed, with probability $\zeta_{t}^{S L}$, and earning the benefit $b_{t}^{S}$ ) and

\footnotetext{
${ }^{12}$ See Gancia and Zilibotti (2005) for a discussion.
} 
if not caught with probability $1-\pi$ (earning the going wage $w_{t}^{S R}$ ). In either case, for simplicity the worker provides the minimum effort level $e_{m}^{R}$.

In equilibrium, workers are indifferent between shirking and not shirking; condition (24) therefore holds with equality and can be solved to give

$$
e_{t}^{R}=1-\left(1-e_{m}^{R}\right)\left[\frac{\zeta_{t}^{S Y}(1-\tau) w_{t}^{S Y}+\zeta_{t}^{S L} b_{t}^{S}}{(1-\tau) w_{t}^{S R}}\right]^{\psi},
$$

with $\psi=\pi \delta_{R} /\left(1-\delta_{R}\right)$. Thus, an increase in the expected wage in the innovation sector relative to its opportunity cost raises the level of effort. For a given wage ratio, an increase in the probability of getting caught shirking (a rise in $\pi$ ) raises also the level of effort. ${ }^{13}$

Using (21), and taking the patent fee and productivity as given, the firm's problem is to maximize profits by setting both wages and employment:

$$
\max _{N_{t}^{S R}, w_{t}^{S R}} \Pi_{t}^{R}=Q_{t} A_{t}^{R}\left[\frac{e_{t}^{R}(1-\varepsilon) N_{t}^{S R}}{\bar{N}}\right]^{\lambda}-\left(1+\varsigma_{t}\right) w_{t}^{S R}(1-\varepsilon) N_{t}^{S R},
$$

subject to (25). The first-order conditions are given by

$$
\begin{gathered}
\lambda\left(N_{t}^{S R}\right)^{\lambda-1}\left(e_{t}^{R}\right)^{\lambda}(1-\varepsilon)^{\lambda} \frac{Q_{t} A_{t}^{R}}{\bar{N}^{\lambda}}=\left(1+\varsigma_{t}\right)(1-\varepsilon) w_{t}^{S R}, \\
\lambda\left(e_{t}^{R}\right)^{\lambda-1} \frac{Q_{t} A_{t}^{R}}{\bar{N}^{\lambda}}\left[(1-\varepsilon) N_{t}^{S R}\right]^{\lambda} \frac{\psi\left(1-e_{t}^{R}\right)}{w_{t}^{S R}}=\left(1+\varsigma_{t}\right)(1-\varepsilon) N_{t}^{S R} .
\end{gathered}
$$

These equations can be combined to give

$$
w_{t}^{S R}=\kappa^{R}\left[\zeta_{t}^{S Y}(1-\tau) w_{t}^{S Y}+\zeta_{t}^{S L} b_{t}^{S}\right]
$$

where $^{14}$

$$
\kappa^{R}=\frac{\left[(1+\psi)\left(1-e_{m}^{R}\right)\right]^{1 / \psi}}{1-\tau}>1 .
$$

Thus, the efficiency wage is proportional to, and higher than, the (expected) opportunity cost of working in the innovation sector. At the optimal wage, the equilibrium level of effort is constant at $\tilde{e}^{R}=1-\left(1-e_{m}^{R}\right)\left(\kappa^{R}\right)^{-\psi}>0$.

\footnotetext{
${ }^{13}$ If effort is independent of relative wages $(\psi=0)$ then $e_{t}^{R}=e_{m}^{R}$.

${ }^{14}$ The Solow condition, which requires $\left(w_{t}^{S R} / e_{t}^{R}\right)\left(d e_{t}^{R} / d w_{t}^{S R}\right)=1$, can be directly established from (27) and (28) and by noting that $d e_{t}^{R} / d w_{t}^{S R}=\psi\left(1-e_{t}^{R}\right) / w_{t}^{S R}$.
} 


\subsection{Government}

The government operates both a general budget and an unemployment insurance fund. It cannot issue bonds and must run balanced accounts in both cases. To finance its general outlays, the government levies a tax on wages at the rate $\tau$. These outlays consist of investment in infrastructure, $G_{t}^{I}$, and spending on other (not directly productive) items, $G_{t}^{O}$. It imposes no fees for its services.

The government's general budget is given by

$$
G_{t}^{I}+G_{t}^{O}=\tau\left\{w_{t}^{U} N_{t}^{U Y}+\left[N_{t}^{S Y}\left((1-\varepsilon) w_{t}^{S Y}-t c_{t}\right)+N_{t}^{S R}\left(w_{t}^{S R}-t c_{t}\right)\right]\right\} .
$$

Shares of spending are constant fractions of government revenues:

$$
G_{t}^{i}=v_{i} \tau\left\{w_{t}^{U} N_{t}^{U Y}+\left[N_{t}^{S Y}\left((1-\varepsilon) w_{t}^{S Y}-t c_{t}\right)+N_{t}^{S R}\left(w_{t}^{S R}-t c_{t}\right)\right]\right\}, \quad i=I, O
$$

where $v_{i} \in(0,1)$. Combining (30) and (31) therefore yields

$$
v_{I}+v_{O}=1 .
$$

Let $\theta_{t}^{h}, h=U Y, S Y, S R$, denote the proportion of employed individuals of category $h$ in the adult population $\bar{N}$, and let $\theta_{t}^{h}, h=U L, S L$, denote the unemployment rate (again, in proportion of $\bar{N}$ ) of labor category $h$; the unemployment insurance fund's budget is given by

$$
\left(b_{t}^{U} \theta_{t}^{U L}+b_{t}^{S} \theta_{t}^{S L}\right) \bar{N}=\varsigma_{t}\left\{w_{t}^{U} \theta_{t}^{U Y}+(1-\varepsilon)\left(w_{t}^{S Y} \theta_{t}^{S Y}+w_{t}^{S R} \theta_{t}^{S R}\right)\right\} \bar{N},
$$

which implies

$$
\varsigma_{t}=\frac{b_{t}^{U} \theta_{t}^{U L}+b_{t}^{S} \theta_{t}^{S L}}{w_{t}^{U} \theta_{t}^{U Y}+(1-\varepsilon)\left(w_{t}^{S Y} \theta_{t}^{S Y}+w_{t}^{S R} \theta_{t}^{S R}\right)} .
$$

Thus, all else equal, a higher benefit rate $\left(b_{t}^{U}\right.$ or $\left.b_{t}^{S}\right)$ raises the payroll contribution rate, thereby reducing labor demand. In turn, the reduction in labor demand (through a fall in employment ratios) mitigates the initial increase in the contribution rate at the initial unemployment and wage rates.

Assuming full depreciation, the stock of public capital evolves according to

$$
K_{t+1}^{G}=\varphi G_{t}^{I},
$$

where $\varphi \in(0,1)$ is an efficiency parameter, which measures the extent to which investment outlays translate into actual public capital (Agénor, 2012). 
To ensure the existence of a nondegenerate solution, the unemployment benefit is set as a linear function of the level of per capita income, so that

$$
b_{t}^{h}=\kappa^{h} \frac{Y_{t}}{\bar{N}},
$$

where $\kappa^{h} \in(0,1)$, with $h=U, S$, is the benefit indexation parameter.

\subsection{The Labor Market}

Wages in the final good sector are set in a monopoly union setting. The centralized trade union's objective is to maximize the expected current income of both types of workers in manufacturing, subject to wage and employment targets. ${ }^{15}$

Specifically, the union sets $w_{t}^{U}$ and $w_{t}^{S Y}$ with the objective of maximizing a utility function that depends on deviations of both employment and wages from their target levels, subject to the manufacturing sector's demand schedule for each type of labor. Normalizing the employment target to zero, the union's utility function takes the standard form

$$
\mathfrak{V}_{t}^{h}=\left(w_{t}^{h}-w_{t}^{h T}\right)^{\xi^{h}}\left(N_{t}^{h}\right)^{1-\xi^{h}}
$$

where $h=U Y, S Y, \xi^{h} \in(0,1)$, and $N_{t}^{h}$ is given in (13). The term $w_{t}^{h T}$ measures the union's target wage, whereas $\xi^{h}$ reflects the relative importance that the union attaches to wage deviations from that target. Maximizing this function with respect to $w_{t}^{h}$ gives the actual wage as a mark-up (which is increasing in $\xi^{h}$ ) over the target wage: ${ }^{16}$

$$
w_{t}^{h}=\left(\frac{1-\xi^{h}}{1-2 \xi^{h}}\right) w_{t}^{h T} .
$$

The target wage for untrained workers is related positively to a government-imposed minimum wage, $w_{t}^{U M}$, and negatively to the unemployment rate for that category of labor, $\theta_{t}^{U L}$ :

$$
w_{t}^{U T}=w_{t}^{U M}\left(\theta_{t}^{U L}\right)^{-\varkappa^{U}}
$$

where $\varkappa^{U}>0$. Thus, when unemployment is high, the probability of finding a job (at any given wage) is low. Consequently, the higher the unemployment rate, the greater the

\footnotetext{
${ }^{15}$ The union's optimization problem is static, in the sense that when it formulates its wage demands it takes the existing capital stock as given and does not internalize the effect of future wages on the firm's decision to accumulate capital — and thus future labor demand. This is tantamount to assuming sequential wage bargaining and the absence of reputational links across periods.

${ }^{16}$ To ensure that $w_{t}^{h}>0$ requires $\xi^{h}<0.5$, a condition that we impose in the parameterisation.
} 
incentive for the union to moderate its wage demands in order to induce firms to increase employment. ${ }^{17}$

In turn, the minimum wage is linearly related to the level of per capita income:

$$
w_{t}^{U M}=w_{0}^{U}\left(\frac{Y_{t}}{\bar{N}}\right)
$$

where $w_{0}^{U}>0$ is an indexation parameter.

Substituting the above expressions into (36) therefore yields

$$
w_{t}^{U}=w_{0}^{U}\left(\frac{1-\xi^{U}}{1-2 \xi^{U}}\right)\left(\frac{Y_{t}}{\bar{N}}\right)\left(\theta_{t}^{U L}\right)^{-\varkappa^{U}} .
$$

The target wage for specialized workers is negatively related as well to the unemployment rate for that category of workers, $\theta_{t}^{S L}$, and linearly related once again to the level of per capita income, $Y_{t} / \bar{N}$, so that $w_{t}^{S Y T}=w_{0}^{S Y}\left(\theta_{t}^{S L}\right)^{-\varkappa^{S}} Y_{t} / \bar{N}$, where $w_{0}^{S Y}>0$ is an indexation parameter. Inserting this result into (36) yields

$$
w_{t}^{S Y}=w_{0}^{S Y}\left(\frac{1-\xi^{S Y}}{1-2 \xi^{S Y}}\right)\left(\theta_{t}^{S L}\right)^{-\varkappa^{S}}\left(\frac{Y_{t}}{\bar{N}}\right) .
$$

The equilibrium condition of the market for untrained labor is given by

$$
N_{t}^{U}=N_{t}^{U L}+N_{t}^{U Y}
$$

where $N_{t}^{U L}$ is the number of unemployed. Equivalently, in terms of ratios to population,

$$
\theta_{t}^{U}=\theta_{t}^{U L}+\theta_{t}^{U Y}
$$

where $\theta_{t}^{U}=N_{t}^{U} / \bar{N}$, which from (8) is equal to $a_{t}^{C}$. Thus, the probability of employment for an untrained individual, $\zeta_{t}^{U Y}$, and the probability of an untrained individual becoming unemployed, $\zeta_{t}^{U L}$, are given respectively by

$$
\zeta_{t}^{U Y}=\frac{\theta_{t}^{U Y}}{\theta_{t}^{U}}, \text { and } \zeta_{t}^{U L}=1-\zeta_{t}^{U Y}=\frac{\theta_{t}^{U L}}{\theta_{t}^{U}} .
$$

The equilibrium condition of the market for (effective) specialized labor is given by:

$$
N_{t}^{S}=N_{t}^{S Y}+N_{t}^{S R}+N_{t}^{S L}
$$

\footnotetext{
${ }^{17}$ This specification, as discussed in Agénor (2006), is consistent with the empirical prediction of models of the wage curve.
} 
or equivalently, in terms of ratios to population,

$$
\theta_{t}^{S}=\theta_{t}^{S Y}+\theta_{t}^{S R}+\theta_{t}^{S L}
$$

The employment and unemployment probabilities for specialized workers are given by

$$
\zeta_{t}^{S Y}=\frac{\theta_{t}^{S Y}}{\theta_{t}^{S}}, \quad \zeta_{t}^{S R}=\frac{\theta_{t}^{S R}}{\theta_{t}^{S}}, \quad \text { and } \zeta_{t}^{S L}=1-\zeta_{t}^{S Y}-\zeta_{t}^{S R}=\frac{\theta_{t}^{S L}}{\theta_{t}^{S}} .
$$

\subsection{Savings-Investment Balance}

Assuming full depreciation $\left(\delta^{P}=1\right)$, the saving-investment balance requires private capital in $t+1$ to be equal to savings in period $t$ by all individuals, employed or unemployed, born in $t-1$ :

$$
K_{t+1}^{P}=\left(s_{t}^{U Y} N_{t}^{U Y}+s_{t}^{U L} N_{t}^{U L}\right)+\left(s_{t}^{S Y} N_{t}^{S Y}+s_{t}^{S R} N_{t}^{S R}+s_{t}^{S L} N_{t}^{S L}\right) .
$$

\section{Balanced Growth Equilibrium}

In this economy, an equilibrium with imperfect competition and unemployment is a sequence of consumption and saving allocations $\left\{c_{t \mid t}^{h, j}, c_{t \mid t+1}^{h, j}, s_{t}^{h, j}\right\}_{t=0}^{\infty}$, for $h=U, S Y, S R$, $j=E, L$, prices of production inputs $\left\{w_{t}^{U}, w_{t}^{S Y}, w_{t}^{S R}, r_{t+1}\right\}_{t=0}^{\infty}$, private capital $\left\{K_{t}^{P}\right\}_{t=0}^{\infty}$, public capital $\left\{K_{t}^{G}\right\}_{t=0}^{\infty}$, existing varieties $\left\{M_{t}\right\}_{t=0}^{\infty}$, prices and quantities of intermediate inputs $\left\{P_{t}^{s}, x_{s, t}\right\}_{t=0}^{\infty}, \forall s \in\left(0, M_{t}\right)$, such that, given initial stocks $K_{0}^{P}, K_{0}^{G}, M_{0}>0$,

a) all individuals, specialized or untrained, employed or unemployed, maximize utility by choosing consumption subject to their intertemporal budget constraint, taking factor prices, the tax rate, and the unemployment benefit as given;

b) firms in the final good sector maximize profits by choosing labor, private capital, and intermediate inputs, taking factor prices as given;

c) intermediate input producers set prices so as to maximize profits, while internalizing the effect of their decisions on the perceived aggregate demand curve for their product;

$d$ ) producers in the innovation sector maximize profits by choosing labor and wages, taking patent prices and productivity as given;

$e$ ) the price of each blueprint extracts all profits made by the corresponding intermediate input producer;

$f$ ) the trade union in the manufacturing sector sets wages so as to maximize its utility, subject to the demand for labor by firms in the final good sector;

$g$ ) the final good market clears, or equivalently savings equals investment; and

h) unemployment of both categories of workers prevails. 
A balanced growth equilibrium is an equilibrium with imperfect competition and unemployment in which

a) $\left\{c_{t \mid t}^{h, j}, c_{t \mid t+1}^{h, j}, s_{t}^{h, j}\right\}_{t=0}^{\infty}$, for $h=U, S Y, S R, j=E, L$, and $K_{t}^{P}, K_{t}^{G}, Y_{t}, M_{t}, w_{t}^{U}, w_{t}^{S Y}, w_{t}^{S R}$, $b_{t}^{h}, h=U, S$, grow at the constant, endogenous rate $1+\gamma$, implying that the knowledgeprivate capital ratio and the public-private capital ratio are constant;

b) the rate of return on capital, $1+r_{t+1}$, is constant;

c) the price of intermediate goods, $P_{t}$, and the patent price, $Q_{t}$, are constant;

$e$ ) the threshold level of individuals who choose to remain untrained, $a_{t}^{C}$, is constant;

$f$ ) the fractions of the specialized and untrained labor force employed in manufacturing, $\theta_{t}^{S Y}$ and $\theta_{t}^{U Y}$, and the fraction of specialized workers employed in the innovation sector, $\theta_{t}^{S R}$, are constant;

g) specialized and untrained unemployment rates, $\theta_{t}^{S L}$ and $\theta_{t}^{U L}$, are constant; and

h) employment and unemployment probabilities, $\zeta_{t}^{U Y}, \zeta_{t}^{S Y}, \zeta_{t}^{S R}$, and $\zeta_{t}^{U L}, \zeta_{t}^{S L}$ are constant.

\section{Properties of the Equilibrium}

A complete analytical solution of the model is provided in Appendix A. A key step in deriving the equilibrium growth rate is to establish the restrictions needed on the congestion parameters in (12). With $m_{t}=M_{t} / K_{t}^{P}$ denoting the knowledge-private capital ratio, equation (12) yields

$$
\begin{gathered}
Y_{t}=(1-\varepsilon)^{\beta^{S}}\left(\theta_{t}^{S Y}\right)^{\beta^{S}}\left(\theta_{t}^{U Y}\right)^{\beta^{U}} N_{t}^{\beta^{S}+\beta^{U}-\omega \zeta_{N}} \\
\times\left(k_{t}^{G}\right)^{\omega}\left\{\Lambda_{1} m_{t}^{(1-\eta) / \eta}\left(\frac{Y_{t}}{K_{t}^{P}}\right)\right\}^{\gamma}\left(K_{t}^{P}\right)^{\alpha+\gamma / \eta+\omega\left(1-\zeta_{K}\right)},
\end{gathered}
$$

where $\Lambda_{1}=\gamma \eta$. To ensure that production is linear in the private capital stock, $\zeta_{K}$ and $\zeta_{N}$ must satisfy the conditions $\beta^{S}+\beta^{U}-\omega \zeta_{N}=0$ and $\alpha+\gamma / \eta+\omega\left(1-\zeta_{K}\right)=1$. As a result, the level of output becomes:

$$
Y_{t}=\frac{\left(k_{t}^{G}\right)^{\omega /(1-\gamma)} \Lambda_{2}}{\left[\left(\theta_{t}^{S Y}\right)^{\beta^{S}}\left(\theta_{t}^{U Y}\right)^{\beta^{U}}\right]^{-1 /(1-\gamma)}}\left(m_{t}^{(1-\eta) / \eta}\right)^{\gamma /(1-\gamma)} K_{t}^{P},
$$

where $\Lambda_{2}=(1-\varepsilon)^{\beta^{S}} \Lambda_{1}^{\gamma /(1-\gamma)}$.

In Appendix A we also show that the model can be condensed in the form of a system consisting of two first-order dynamic equations in terms of the knowledge-private capital ratio, $m_{t}$, and the public-private capital ratio, $k_{t}^{G}$, as well as 9 core static equations, in terms of the output-private capital ratio, $Y_{t} / K_{t}^{P}$, the patent price, $Q_{t}$, the threshold level of 
ability (or equivalently the share of untrained workers), $a_{t}^{C}$, the shares of specialized workers in final good production and innovation activities, $\theta_{t}^{S Y}$ and $\theta_{t}^{S R}$, the share of untrained workers in final good production, $\theta_{t}^{U Y}$, the shares of specialized and untrained workers in unemployment, $\theta_{t}^{S L}$ and $\theta_{t}^{U L}$, and the payroll contribution rate, $\varsigma_{t}$. The steady-state growth rate, $1+\gamma$, is shown to be $\mathrm{e}^{18}$

$$
1+\gamma=\left(e^{R}\right)^{\lambda}(1-\varepsilon)^{\lambda}\left(k^{G}\right)^{\phi_{1}^{R}}\left(\theta^{S R}\right)^{\lambda} .
$$

Given the complexity of the system, stability of the economy cannot be studied analytically. However, it is established numerically (based on the calibration discussed next) by solving for an initial balanced growth equilibrium that satisfies the properties defined earlier and verifying that following a shock, or combination of shocks, the system converges to a new equilibrium in a finite number of periods.

\section{Calibration}

To study the impact of labor market reforms, we calibrate the model for a stylized middleincome economy, based on the averages for the five upper-income Latin American countries mentioned in the introduction (Argentina, Brazil, Chile, Colombia, and Peru). ${ }^{19}$ Together, these countries accounted for about 75 percent of the region's GDP over the period 200-14. They have a relatively small innovation sector (both in terms of employment and capacity to create knowledge) and are characterized by significant labor market rigidities and high levels of unemployment, caused largely by permanent, structural factors rather than cyclical determinants, as documented by the Inter-American Development Bank (2004), Ball et al. (2011), and the International Labour Organization (2017). The main sources of data are the Inter-American Development Bank (IADB), the International Labour Organization (ILO), and the World Bank. For convenience, population is normalized to unity.

On the household side, estimates based on household surveys by Gandelman (2015) are used to set the savings rate $\sigma$ at 0.138 . The average school life expectancy at tertiary level for the five Latin American economies is 3.07 years, which gives $\varepsilon=0.123$. To account for more costly and less efficient training, and in the absence of data, the training cost $\mu$ is

\footnotetext{
${ }^{18}$ From the equations in Appendix A, and given that all stock variables grow at the same rate in equilibrium, other equivalent forms for the steady-state growth rate can of course be defined.

${ }^{19}$ We do not include Mexico in our sample because of its low unemployment rate.
} 
set at 0.12, and the efficiency of training $\chi$ at 0.5, as in Agénor and Alpaslan (2014). In the final good sector, the elasticity of production with respect to the public-private capital ratio $\omega$ is set at 0.24, in line with the general equilibrium estimates of Agénor and Neanidis (2015). The elasticity parameter with respect to private capital, $\alpha$, is set equal to 0.35 . This is the average value for the five Latin American economies used for instance in the growth accounting exercises of Loayza et al. (2005). In line with studies using growth models for Latin America, we set $\beta^{U}=0.20$ and $\beta^{S}=0.35$, so that $\gamma=0.1$ again. $^{20}$

In the intermediate good sector, the substitution parameter, $\eta$, is set at 0.25 , which corresponds to the value used by Agénor and Neanidis (2015) to examine innovation-driven growth. This value implies therefore a low elasticity of substitution (about 1.33) between intermediate goods, a well-documented feature for Latin American economies. In the same vein, in the innovation sector $\phi_{1}^{R}$ is set at 0.3 , which is consistent with higher range of estimates obtained by Agénor and Neanidis (2015). To parameterize for a benchmark case where research monitoring is weak, the probability of being caught shirking is set at slightly below 5 percent, $\pi=0.048$. This yields $\psi=0.43$.

For the government, to be consistent with the model definition, using data from World Bank's World Development Indicators (WDI) within the period of 2006-13, the effective tax rate on wages, $\tau$, is calculated by dividing the estimated weighted average ratio of tax revenues to GDP with the average share of labor income estimated for the corresponding sample of countries by Guerriero (2012). This yields $\tau=0.123$. The efficiency parameter of government investment, $\varphi$, is calibrated using the 'wastefulness of government spending' indicator in the Global Competitiveness Report index, which yields $\varphi=0.4$. This estimate of $\varphi$ is close to the median value obtained by Dabla-Norris et al. (2012) in their study of the efficiency of public investment in developing countries. The share of public spending on infrastructure, $v_{I}$, is estimated in two steps, based on the data on total infrastructure investment as a proportion of GDP compiled by Calderon and Servén (2010) and Carranza et al. (2014). The private component of total investment, obtained from the World Bank's Private Participation in Infrastructure Database, is first subtracted to obtain the share of public infrastructure investment as a proportion of GDP. This figure is then multiplied by the inverse of the ratio of non-interest government expenditure to GDP to obtain an

\footnotetext{
${ }^{20}$ See Agénor and Canuto (2015a) for Brazil, and Ferreira et al. (2013) for Latin America.
} 
estimate of $v_{I}$ for each of the five Latin American economies. The average value for the five economies for the period 2006-13 gives $v_{I}=0.069$, or equivalently 2.0 percent of GDP.

Regarding the labor market, in the absence of Latin America-specific estimates, we use the European estimates in Montuenga et al. (2003), who estimated the wage elasticity with respect to unemployment rate to be approximately -0.12 . This means $\varkappa^{U}=\varkappa^{S}=0.12$. The minimum wage shift parameter, $w_{0}^{U}$, is calibrated based on the average ratio of the gross monthly minimum wage over gross monthly earnings, as provided in ILO Statistics. This gives $w_{0}^{U}=0.546$. For $w_{0}^{S Y}$, the median wage differentials between secondary-primary and secondary-tertiary are used (see Inter-American Development Bank (2004, Table 1.8)) to estimate an average value for wage dispersion in the five Latin American economies. This yields 0.153, which implies, solving again (39) implicitly, $w_{0}^{S Y}=0.699$. In terms of unemployment benefits (which cover in reality a fairly limited number of workers), estimates by Cortazar (2001) and Ferrer and Riddell (2009) suggest that for the group of countries under consideration, unemployment insurance represents from 0.12 to 2.5 times the minimum wage. Multiplying by $w_{0}^{U}=0.546$ yields a range of $0.06-0.82$ for $\kappa^{U}$ and $\kappa^{S}$. Mid-range value of $\kappa^{U}=\kappa^{S}=0.4$, which also happens to be the value commonly used in partial equilibrium model with unemployment insurance (see Heer and Morgenstern (2005)), is therefore used. Lastly, for the union wage mark-up, the Inter-American Development Bank (2004) documents that unions in South America increase their members' earnings by anywhere between 5 and 10 percent. Setting the wage mark-up to 1.1, and again solving (36) backward yields $\xi^{U}=\xi^{S Y}=0.08$.

In terms of initial steady-state values, the labor shares are estimated using data from ILO and the World Bank. The share of untrained workers in the population, $\theta^{U}$, is set equal to 0.795 , which yields $\theta^{S}=0.184$. The share of effective specialized workers in innovation, $\theta^{S R}$, is estimated by dividing the average number of researchers over the total workforce for the five economies over 2006-13, yielding $\theta^{S R}=0.004$. The share of unemployed specialized workers, $\theta^{S L}$, is set equal to 0.071 , based on ILO data. By implication, $\theta^{S Y}=0.109$. The unemployment rate for untrained workers, $\theta^{U L}$, is also obtained from ILO data and is set at 0.087. These data therefore imply that $\theta^{U Y}=0.708$, and the aggregate unemployment rate is now 0.0791. To estimate for the misallocation of talents, in the absence of Latin American data, we first work out a $a^{R}$ value using (10), based on the OECD-average proportion of 
workers who are overqualified. This yields $a^{R}=0.952 .{ }^{21}$ Theoretically, this threshold value, $a^{R}$, should be the same across all economies. Using this, and the calibrated values for $\theta^{S R}$ and $\theta^{S Y}$, we can solve backward using the formula, $\left(\theta^{R}-\theta^{S R}\right) / \theta^{S Y}$, to yield the initial degree of talent misallocation at 0.392. Compared to the OECD data, this would mean that there are a lot more overqualified workers in the final good sector of a middleincome economy, consistent with recent theories of middle-income traps (Agénor, 2017). The firms' payroll contribution rate, $\varsigma$, is set at $0.052 .{ }^{22}$ The initial relative wage ratio is estimated at 0.75 based on ILO data, implying that the initial expected wage premium is at 1.333. The public-private capital ratio calculated for Brazil by Agénor and Canuto $(2015 a), k^{G}=0.147$, is used as a proxy for the group average. The final output-private capital ratio, $Y / K^{P}$, is calibrated using the private capital-GDP ratios for Argentina, Brazil and Chile estimated by Tafunell and Ducoing (2016). This yields $Y / K^{P}=0.429$. The knowledge-private capital ratio, $m$, is normalized to 0.1 . Lastly, the annual growth rates for final output and capital in the initial steady state equal to 3.9 percent, based on the GDP-weighted average growth rate of the five economies during 2006-13.

\section{$6 \quad$ Policy Experiments}

We now consider a series of individual labor market policies - a reduction in the minimum wage, a cut in unemployment benefit rates, and a reduction in the union's wage mark-up. In addition, we also consider a policy aimed at promoting the accumulation of human capital (a cut in training cost). These policies have been discussed extensively in recent years. ${ }^{23}$ All shocks are permanent and their impact is measured in terms of a few key variables - the supply of untrained workers, the effective supply of specialized workers (both total and in the innovation sector), the expected wage premium (which determines training decisions),

\footnotetext{
${ }^{21}$ Using OECD figures calculated on the basis of the EU Labour Force Survey, we first set $\theta^{R}$ as equal the "proportion of workers whose educational attainment level is higher than the level required in their job (as measured based on the modal education level for all workers in the same occupation)." The OECD average over 2006-13 equals 0.189. Based on that value, and knowing that from $(10) \theta^{R}=\left[1-\left(a^{R}\right)^{2}\right] / 2$, we get $a^{R}=0.952$. This value should be the same across different populations, regardless of income levels.

${ }^{22}$ While payroll taxes represent on average of 31 percent of wages in Latin America (see Lora and Fajardo (2012)), only the portion that employers contribute to the unemployment/severance fund is accounted for here.

${ }^{23}$ See Inter-American Development Bank (2004), World Bank (2012a, 2012b), Adascalitei and Pignatti Morano (2015) and International Monetary Fund (2016) for instance.
} 
unemployment rates (total and for both categories of workers), the payroll contribution rate, and the growth rate of final output.

To measure the efficiency gains of reforms in terms of factor allocation, the index of misallocation of talent defined earlier is used. To measure welfare, discounted utility across an infinite sequence of generations is used (see De la Croix and Michel, 2002, p. 91):

$$
\mathcal{W}_{t}=0.2 \sum_{h=0}^{\infty} \Lambda^{h}\left(V_{t+s}^{U, E}+V_{t+h}^{U, L}+V_{t+h}^{S Y, E}+V_{t+h}^{S R, E}+V_{t+h}^{S, L}\right)
$$

where $\Lambda \in(0,1)$ is the social discount factor and $V_{t}^{h, j}$ is the indirect utility function for agent $j, h$ at $t$, where $h=U, S Y, S R$ and $j=E, L$. Thus, the utility of agents in each generation in all five states - untrained workers employed or unemployed, specialized workers employed in the final good sector and innovation activities or unemployed-are equally weighted. ${ }^{24}$ For tractability, we restrict our analysis to the balanced growth path; Appendix B provides an approximation to (48) along that path, with $\Lambda$ set to the same value used for households.

Simulation results (impact and steady-state effects) are summarized in Table 3, whereas Figure 2 shows the impact and steady-state effects for all experiments.

\subsection{Reduction in the Minimum Wage}

Consider a reduction in the minimum wage, measured by a 5 percent drop in the shift parameter $w_{0}^{U}$. The reduction in the cost of untrained labor increases demand not only for that category of workers but also (due to gross complementarity) for specialized labor in manufacturing. At the initial level of wages, the unemployment rate falls and the employment probability rises for both categories of workers. However, the expected wage for specialized workers increases by more than the expected wage for untrained workers, thereby creating incentives to invest in advanced training. The proportion of untrained (specialized) workers therefore falls (increases) on impact. The increase in specialized employment occurs in both the final good and innovation sectors, though not all specialized labor from the expansion are absorbed, resulting in a slight increase in long-run specialized unemployment rate. The long-run drop in unemployment is particularly large for untrained workers, of the order of

\footnotetext{
${ }^{24}$ Alternatively, weights based on steady-state relative shares of each group of workers in the labor force (which deviate from baseline values as a result of the labor reallocation effects associated with each experiment), could be used. Qualitatively the results are broadly similar to those reported here.
} 


\section{0 percent..$^{25}$}

Higher employment for both types of workers translate into a reduction in the payroll contribution rate, which magnifies the expansion in labor demand in manufacturing. Although the initial fall in unemployment tends to raise the union's target wages in the manufacturing sector - thereby mitigating the initial effect of a lower minimum wage - the increased demand for both types of workers tends to promote activity and economic growth, both on impact and in the long run. However, the long-run effects are fairly small.

Higher wages for specialized workers in manufacturing imply higher wages in the innovation sector as well, to maintain effort there. This helps to increase the share of that type of labor engaged in innovation activity, thereby mitigating the misallocation of talent, by a magnitude of 0.4 percentage points in the long run. In addition, welfare improves moderately. In terms of their magnitude, both results reflect a small increase in employment in the innovation sector, a weak effect on the expansion of varieties of intermediate goods, and therefore a small impact on growth in the long run. Overall, lower minimum wages do not necessarily harm growth and welfare - in contrast to the predictions of some small analytical models, such as Cahuc and Michel (1996) - but their effects on these variables, given our calibration, are not quantitatively large.

\subsection{Reduction in Unemployment Benefit Rates}

We consider three separate experiments with respect to a scaling down in unemployment benefit indexation: a) a reduction in the indexation parameter for only untrained workers, b) a reduction for only specialized workers, and $c$ ) a reduction for both type of workers. Specifically, we consider cuts in $\kappa^{U}$ and $\kappa^{S}$ by 10 percent (from 0.40 to 0.36 ) each, and a joint reduction in $\kappa^{U}$ and $\kappa^{S}$ of the same magnitude. These experiments allow us to examine and compare the effects of asymmetric adjustments in unemployment insurance schemes, as well as the case of an across-the-board reform.

A reduction in the benefit rate for untrained workers lowers their expected wage at the initial level of employment. It therefore raises the education premium and incentives to undergo training. As a result, the share of untrained (specialized) workers falls (increases).

\footnotetext{
${ }^{25}$ The reduction in unemployment is consistent with the evidence reviewed by Neumark and Wascher (2006) although, as they point out, the wide range of estimates makes the precise identification of the magnitude of this effect difficult.
} 
The opposite occurs for a reduction in the benefit rate for specialized workers. However, in both cases aggregate unemployment falls, both on impact and in the long run. This stems from the fact that the direct effect of a lower wage is (as a result of gross complementarity) to stimulate the demand for both types of labor. This effect, which is magnified by a reduction in the payroll contribution rate needed to ensure that the unemployment fund's budget is balanced, persists over time as well. Long-run specialized (untrained) unemployment rate increases slightly when the indexation parameter is reduced for the untrained (specialized) workers. This is due to a weaker gross complementarity effect and a smaller expansion in the innovation sector, which mitigates its capacity to absorb the increase in specialized labor.

On impact, the growth rate of final output falls. The reason is that the drop in benefits for the unemployed has an adverse effect on savings, which reduces investment and capital accumulation in the short run. Over time, however, two offsetting general equilibrium effects kick in: lower benefits (for untrained workers) improve incentives for individuals to acquire training, whereas a lower contribution rate raises labor demand. In the long run the net effect of the policy is in fact positive - albeit fairly weak. Although talent misallocation is mitigated, welfare falls (for either shock) essentially because the unemployed are worse off. The joint reduction in unemployment benefit indexation gives results that are qualitatively similar to those obtained in the individual experiments, and in this instance, unemployment falls - both at the aggregate level and in its components.

The conflicting effect on long-run growth and welfare has not been documented in previous contributions. It suggests that a reduction in unemployment benefit indexation, while effective in terms of reducing unemployment for both types of labor, may need to be accompanied by other measures aimed at mitigating their potential adverse impact on household well-being.

\subsection{Reduction in the Union's Wage Mark-Up}

Consider a reduction in the mark-up over the target wage for both untrained and specialized workers, as measured by the parameters $\xi^{U}$ and $\xi^{S Y}$, respectively (see (36)). This experiment involves a uniform 37.5 percent cut in these parameters, from 0.08 to $0.05 .^{26}$

\footnotetext{
${ }^{26}$ It is important to understand that $\xi^{U}$ and $\xi^{S Y}$ are preference parameters, which are not directly under the control of policymakers. However, we assume that, through appropriate legislation, public authorities
} 
The overall general equilibrium effects of this specific labor market policy are small. The $\xi^{U}$ shock is effective in reducing unemployment rate for the untrained, but negligible for the specialized unemployment rate. For the $\xi^{S Y}$ shock, the opposite is observed. In the long run the growth effects are also fairly small. Welfare deteriorates when the mark-up for specialized workers is reduced, but improves slightly when the mark-up for untrained workers is lowered. Again, these results suggest that, taken in isolation, these policies do not have substantial effects on growth and unemployment in the long run, and may be detrimental to welfare.

\subsection{Reduction in Training Cost}

Finally, consider a policy designed to reduce across the board the cost of specialized training for individuals, paid for by a reallocation of outlays within the unproductive component of public spending. The policy once again has no direct fiscal effects and is measured by a reduction in $\mu$ by 5 percent, from 0.120 to 0.114 . The size of this shock is sufficient to illustrate the issues at stake.

A reduction in training costs generates a large increase in the supply of specialized workers by 3.8 percentage points in the long run, a fraction of which being absorbed in the innovation sector. This increase in supply occurs despite the mitigating effect on wages for that category of workers and a drop in the expected wage premium. The reduction in the share of untrained workers has a sizable effect on their unemployment rate; however, the large increase in the supply of specialized workers leads over time to a higher unemployment rate for them (by 3.2 percentage points in the long run). The thrust of these results is that promoting human capital accumulation without adequate measures aimed at encouraging simultaneously a sustained expansion in labor demand may create an absorption problem or oversupply of specialized labor in the long run.

In addition, the positive effect on the rate of economic growth is small both on impact and in the long-run. The reason, as noted earlier, is that the net benefit of an increase in the supply of specialized workers is muted, due to a smaller expansion in labor demand in the innovation sector. The increase in the specialized unemployment rate also results in a higher payroll contribution rate, which mitigates the increase in labor demand and dampens

can induce trade unions to mitigate their wage demands, and this requires, in our setting, a change in $\xi^{U}$ and $\xi^{S Y}$. 
steady-state growth. Nevertheless, and despite the increase in specialized unemployment, welfare improves because employed untrained workers and both types of unemployed workers gain from this policy. For the former, this is because wages are ultimately higher than initially. For the unemployed, this is because unemployment benefits are higher along the equilibrium path, due to higher steady-state growth.

Evidence on the oversupply problem highlighted in our simulation results is consistent with the extensive microeconomic literature on overeducation, which has been reviewed by Leuven and Oosterbeek (2011). It is also an important problem in Latin America, including for the countries in our sample. In Brazil for instance, Marioni (2018) found that over the period 2006-13, 24.7 percent of employed workers in the formal labor market were overeducated. In Colombia, as documented by Mora (2008), that proportion was 14 percent in 2006. Our analysis suggests that the main cause of the overeducation problem in the region may have been deliberate public policies aimed at expanding higher education and making it more affordable to all, by reducing tuition fees in universities.

Indeed, the number of new universities or university programs in the region has expanded steadily since the early 2000s, to reduce the real effective cost of tertiary education. According to Camacho et al. (2016), between 2005 and 2010, 308 and 74 new universities were created in Brazil and Peru, while in Colombia and Chile the expansion was in the form of a boost in programs offered by existing institutions. For instance, in Brazil, despite its public university entrance examination system, vestibular, remains highly competitive, the Ministry of Education has implemented various policies since the early 2000s aimed at reducing the real cost of higher education, resulting in enrollments in Brazilian universities to skyrocket from 3 million to 7.8 million students. ${ }^{27}$ Similar rapid expansions were also observed for the other economies in our sample, as discussed in Ferreyra et al. (2017). While this expansion resulted in many households having greater access to tertiary education, with the supply of skilled jobs lagging behind, it has caused a decline in returns to human capital, hence the absorption problem.

The negative correlation between the incentive to acquire skills and the supply of specialized workers induced by a reduction in the cost of training, as predicted here, is consistent

\footnotetext{
${ }^{27}$ These include Programa de Financiamento Estudantil initiated in 1999, which is a student loans scheme covering 70 percent of tuition fees charged at a very low interest, and Programa Universidade para Todos, implemented in late 2004, which provides incentives to private universities to allocate their unfilled places free of charge to low-income students.
} 
with an inverse association between increases in the number of university graduates and the wage premium. The model also predicts that more university graduates may lead to higher open unemployment. Evidence to support this result is more difficult to come by for at least three reasons. First, higher unemployment rates for new university graduates often result from mismatches between supply and demand for particular skills (for instance, liberal arts), or low quality standards - an important problem in Latin America, as noted by Yamada (2015) - rather than an across-the-board lack of demand for labor, as predicted by our experiment. Second, rather than open unemployment, in practice university graduates may choose to be employed in occupations that do not fully exploit their skill levels, which therefore translates into underemployment or disguised unemployment. ${ }^{28}$ Finally, graduates may also choose to migrate abroad, a form of brain drain. Although the model does not explicitly capture any of these possibilities it does nevertheless draw attention to the adverse labor market effects of an oversupply of skills, due to a low effective cost of education promoted by government subsidies. Social demands to expand access to higher education may ultimately prove counterproductive.

\section{Composite Reform Programs}

The foregoing analysis suggests that reforms may entail dynamic trade-offs: they can have adverse effects on the labor market and growth on impact, despite improving these outcomes in the long run. This trade-off could induce a government motivated by short-term electoral considerations to postpone, or abandon altogether, the implementation of structural reforms. In addition, growth and welfare may move in opposite directions in the long run, as illustrated in the case of a reduction in the degree of indexation of unemployment benefits and a cut in the trade union's mark-up on specialized workers' wage target. A natural issue to address therefore is to what extent a combination of measures - assuming that it is politically feasible - can, by exploiting policy externalities, mitigate the contrasting effects associated with individual reforms.

Accordingly, we now consider alternative composite reform programs involving a combination of the individual policies discussed earlier. In addition, we examine the extent to

\footnotetext{
${ }^{28}$ The possibility that underemployment may result from overeducation is also noted by Leuven and Oosterbeek (2011).
} 
which composite programs designed to reduce unemployment and promote growth would benefit from an increase in public infrastructure investment. This issue has been much discussed in Latin America, with the shortage of basic infrastructure (including core internet access) remains at large and calls for higher public investment have been consistently vocal (Serebrisky et al. (2015)).

\subsection{Core Programs}

Two core composite reform programs are considered first. In both of them we assume that the key objectives of policymakers are to reduce unemployment and to promote skills acquisition to support innovation-driven growth. Given that the distribution of high-ability individuals in the population is fixed, the latter objective can be achieved only by raising the productivity of those currently employed in the innovation sector, in order to induce higher wages and reduce the misallocation of talent. The combination of policies considered, although fairly targeted (given our focus on structural, rather than cyclical, unemployment), is consistent with long-standing calls for comprehensive programs of labor market reforms, as noted earlier.

The first program, denoted Program A, consists of pure labor market reform measures. It involves a cut in the minimum wage, as measured by a 10 percent decrease in the shift parameter $w_{0}^{U}$, a reduction in the unemployment benefit indexation parameters, $\kappa^{U}$ and $\kappa^{S}$, by 6.25 percent (from 0.4 to 0.375 ), and a 37.5 percent cut in the union's untrained wage preference parameter $\xi^{U}$ (a drop from 0.08 to 0.05 ). ${ }^{29}$

The second program, Program B, adds human capital-promoting policies to these measures, to exploit potential gains associated with a skills expansion. Specifically, in addition to the measures in Program A, Program B adds an increase in specialized training time, as measured by $\varepsilon$, and a reduction in the specialized training cost, $\mu .^{30}$

The impact and steady-state effects of both programs are shown in Table 4 . The outcome of the combined shocks is, naturally enough, a composite of the features outlined earlier. The effects of Program A, which consists of pure labor market reforms, are

\footnotetext{
${ }^{29}$ We consider an across-the-board cut in unemployment benefit indexation, even though we assume that reforms mainly target untrained unemployment, because this is the way these policies are implemented in practice.

${ }^{30}$ This translates into a rise in $\varepsilon$ from 0.123 to 0.15 and a fall in $\mu$ from 0.120 to 0.114 .
} 
clear: reductions in both untrained and specialized unemployment rates in the steady state. Specifically, the former (latter) drops by 4.9 percent ( 0.1 percent). There are also reduced misallocation of talent, small gains in both overall specialized workers and the proportion employed in the innovation sector (despite the increase in the wage premium), weak growth effects, and a deterioration in social welfare. This last result is largely due to the unemployed being worse off from the benefits cut.

As expected, the results for Program B show a fairly significant increase (reduction) in the supply of specialized (untrained) workers - of the order of $3.8(-4.9)$ in the long runand reduced misallocation of talent. Nevertheless, the change in welfare remains negative, and in the long run the economy suffers from a higher unemployment rate for specialized labor-the oversupply problem discussed earlier.

In this setting, the response to this issue is to either a) lower supply, by reducing incentives to accumulate human capital, or b) expand demand, by implementing additional policies. Regarding a), making the reduction in the cost of training in Program B smaller obviously leads to lower specialized unemployment in the long run. More interesting in the current economic context is to focus on $b$ ), by considering next whether a concomitant increase in public investment may provide the required stimulus.

\subsection{Infrastructure Investment}

We now consider whether comprehensive labor market reform programs perform better when accompanied by an increase in public infrastructure investment. The important point about this type of spending is that it has both demand-side effects (in the short run) and supply-side effects (in the longer run) by boosting directly the economy's capacity to produce and by stimulating private investment through a higher marginal product of capital. In addition, in our setting improved access to infrastructure helps to promote innovation activity, especially through its impact on knowledge networks, as emphasized in the recent literature. ${ }^{31}$ In that sense, therefore, the provision of public capital is also a productivity-enhancing measure for research activities.

To examine this issue, an additional reform program is considered: Program C, which

\footnotetext{
${ }^{31}$ See Agénor (2017) and the references therein. The effects of an increase in public investment, considered in isolation, are shown in Table 3; these effects are faily muted and show again conflicting effects on growth and welfare.
} 
adds to Program B a 20 percent increase in the share of public spending on infrastructure, $v_{I}$, from 0.069 to 0.083 . The impact and long-run effects of this program are shown also in Table 4. While the specialized unemployment rate does fall marginally, it is insignificant and the absorption problem is only slightly mitigated. Moreover, the change in welfare remains negative.

As noted earlier, addressing the labor absorption issue could be achieved by reducing incentives to acquire skills - namely, by keeping the cost of training high. The question here is whether more ambitious policies aimed at increasing labor demand in both the innovation and final good sectors can prevent a rise in specialized unemployment - even when training costs are lowered by as much as before. Indeed, consider Program $\mathrm{C}$ and suppose that public investment in infrastructure is now increased from 2.0 percent of GDP to 6.2 percent - which translates into an increase in $v_{I}$ from 6.9 percent of noninterest public expenditure to 21 percent. This value is consistent with the upper range of estimates reported by Serebrisky et al. (2015, p. 7) and deemed necessary in a number of policy reports to eliminate Latin America's infrastructure gap with respect to East Asia. In addition, suppose that through governance reforms public investment efficiency, as measured by $\varphi$, is increased in all countries from 0.4 to the level of Brazil's, as estimated by Dabla-Norris et al. (2012, Table 1), that is, 0.78 . The higher stock of public capital contributes to higher productivity in both the final good and innovation sectors (with the latter also benefiting from increased monitoring intensity), which improves the economy's ability to absorb specialized labor. In addition to significantly higher long-run growth (from 0.3 percentage points in Table 4 to 2.4 points) this program leads to an increase in specialized unemployment of only 1.1 percentage points (compared to 2.6 in Table 4). However, this combination of policies does not solve the absorption problem. ${ }^{32}$ The broader lesson from this experiment is therefore that, although investing in infrastructure and improving efficiency in public spending are important to promote labor demand and growth, caution is also needed in promoting higher education through reductions in training costs, to avoid creating an oversupply of specialized workers. In many of these countries, improving the quality of education may prove more effective.

\footnotetext{
${ }^{32}$ Moreover, it is an open question as to whether, in practice, a program involving a permanent increase in the ratio of investment to GDP to more than 6 percent is sustainable politically.
} 


\subsection{Policy Externalities}

Finally, a question worth asking is to what extent composite reform programs generate longrun gains that exceed those generated by independent policies. This issue can be addressed in a simple manner by adding up the steady-state results for each individual policy in a composite program with respect to a particular set of variables, and comparing the aggregate numbers with those reported in Table 4 for the relevant program. The difference between the latter and the sum of individual effects gives a measure of interactions between reforms and (depending on its sign) whether they complement or offset each other, that is, whether policy externalities are positive or negative.

For Program C for instance, the sum of partial effects gives a total of 0.0029 for the growth rate (compared to 0.0031 in Table 4), -0.0509 for the aggregate unemployment rate (compared to -0.0373 ), and -0.1259 for social welfare (compared to -0.1207 ). Whether externalities are positive or negative the benefits of comprehensive programs depends therefore on which outcomes one chooses to focus on; in terms of growth, integrated programs perform better because they generate positive externalities. In terms of unemployment or welfare, however, they perform worse. ${ }^{33}$ Intuitively, policies aimed at cutting unemployment benefits and diluting union's ability to impose excessive wages for untrained workers tend to be associated with drops in wages and consumption for the unemployed and untrained groups - despite the fact that they are complementary to other policies in promoting innovation and specialized employment. Similarly, while combining skills expansion policies (cuts in training cost) with conventional labor market policies tends to create positive externalities in terms of growth and talent allocation, these policies also produce counteracting effects on the specialized wage premium. Thus, instead of a complementarity effect, they generate a negative externality which contributes to weaker outcomes for the composite program in terms of its impact on (untrained) unemployment and welfare.

\section{Concluding Remarks}

The main implications of this paper were summarized in the introduction and need not be repeated here. We therefore conclude by pointing out that the model could be extended to

\footnotetext{
${ }^{33}$ Similar results hold for the other composite programs considered earlier. They are not reported here to save space.
} 
account for other types of labor market distortions, such as state-contingent firing costs and severance payments, deskilling of the labor force associated with unemployment, as well as a positive effect of a higher share of more educated workers on life expectancy and savings (and thus on economic growth), and various other forms of active labor market policies (see Almeida et al. (2012) and Duval and Furceri (2018)). In particular, hiring and firing regulations, and hiring costs, have been shown to have an adverse effect on unemployment, especially when search and matching considerations are important; $;^{34}$ their implications for growth and welfare, however, are less well understood.

A more systematic effort to integrate political economy considerations in assessing the performance of labor market reforms in growth models would also be warranted. Observers have often argued that the costs of these reforms are incurred up front and concentrated on specific groups, whereas their benefits materialize later and are both more diffuse and less predictably allocated among workers and households. In addition, conflicting growth and welfare effects may well lead to organized resistance to reform. A key challenge then is to create the political consensus needed to confront powerful vested interests and mitigate dynamic trade-offs between (short-term) costs and (longer-term) gains.

At the same time, if specific labor market reforms fail to produce broad benefitsas suggested by some of our numerical experiments - political viability may well require implementing reform programs that eschew them and focus instead on upfront measures that matter more for productivity, including better access to infrastructure, which can also help to promote innovation. Put differently, with limited political capital and little capacity to compensate losers in the short run, pursuing a wide array of labor market reforms at once may prove costly and ineffective. Moreover, even when there is broad support for reform, weak administrative capacity and inadequate governance - key constraints in many middle-income countries - militate in favor of a narrow reform agenda.

\footnotetext{
${ }^{34}$ See Bernal-Verdugo et al. (2012) and Millán et al. (2014) for some supportive evidence. However, other studies provide a mixed picture; see International Labour Office (2012) for a discussion.
} 


\section{References}

Adascalitei, Dragos, and Clemente Pignatti Morano, "Labour Market Reforms since the Crisis:

Drivers and Consequences," Research Department Working Paper No. 5, International Labour Office (October 2015).

Agénor, Pierre-Richard, "The Analytics of Segmented Labor Markets," in Adjustment Policies,

Poverty and Unemployment: The IMMPA Framework, ed. by Pierre-Richard Agénor,

Alejandro Izquierdo, and Henning Tarp Jensen, Blackwell Publishing (Oxford: 2006).

—-, Public Capital, Growth and Welfare, Princeton University Press (Princeton, N.J: 2012).

_ - "Caught in the Middle? The Economics of Middle-Income Traps," Journal of Economic Surveys, 31 (July 2017), 771-91.

Agénor, Pierre-Richard, and Joshua Aizenman, "Macroeconomic Adjustment with Segmented

Labor Markets," Journal of Development Economics, 58 (April 1999), 277-96.

Agénor, Pierre-Richard, and Baris Alpaslan, "Infrastructure and Industrial Development with

Endogenous Skill Acquisition," Working Paper No. 195, Centre for Growth and Business

Cycle Research (October 2014).

Agénor, Pierre-Richard, and Otaviano Canuto, "Gender Equality and Economic Growth in

Brazil: A Long-Run Analysis," Journal of Macroeconomics, 43 (March 2015a), 155-72.

"Middle-income Growth Traps," Research in Economics, 69 (December 2015b), 641-60.

Agénor, Pierre-Richard, and Kyriakos Neanidis, "Innovation, Public Capital, and Growth," Journal of Macroeconomics, 44 (June 2015), 252-75.

Almeida, Rita, Jere Behrman, and David Robalino, The Right Skills for the Job: Rethinking Policies for Workers, World Bank Publications (Washington DC: 2012).

Ball, Laurence, Nicolás De Roux and Marc Hofstetter, "Unemployment in Latin America and the Caribbean," Working Paper No. 11/252, International Monetary Fund (November 2011).

Bernal-Verdugo, Lorenzo E., Davide Furceri, Dominique M. Guillaume, "Labor Market Flexibility and Unemployment: New Empirical Evidence of Static and Dynamic Effects," Working Paper No. 12/64, International Monetary Fund (March 2012).

Bhattacharyya, Chandril, and Manash R. Gupta, "Unionised Labour Market, Unemployment Allowances, Productive Public Expenditure and Endogenous Economic Growth," Metroeconomica, 66 (July 2015), 397-425.

Böhm, Sebastian, Volker Grossmann, and Thomas M. Steger, "Does Expansion of Higher Education Lead to Trickle-down Growth?," Journal of Public Economics, 132 (December 2015), 79-94.

Bucci, Alberto, Fabio Fiorillo, and Stefano Staffolani, "Can Market Power Influence Employment, Wage Inequality and Growth?," Metroeconomica, 54 (May 2003), 129-60.

Cacciatore, Matteo, and Giuseppe Fiori, "The Macroeconomic Effects of Goods and Labor Market Deregulation," Review of Economic Dynamics, 20 (March 2016), 1-24. 
Cahuc, Pierre, and Philippe Michel, "Minimum Wage, Unemployment and Growth," European Economic Review, 40 (August 1996), 1463-82.

Calderón, César, and Luis Servén, "Infrastructure in Latin America," Policy Research Working Paper No. 5317, World Bank (May 2010).

Camacho, Adriana, Julián Messina, and Juan Pablo Uribe, "The Expansion of Higher Education in Colombia: Bad Students or Bad Programs?," Discussion Paper No. 452, InterAmerican Development Bank (April 2016).

Carranza, Luis, Christian Daude, and Angel Melguizo, "Public Infrastructure Investment and Fiscal Sustainability in Latin America: Incompatible Goals?" Journal of Economic Studies, 41 (January 2014), 29-50.

Chang, Juin-jen, and Hsiao-wen Hung, "Trade Unions, Unemployment, Economic Growth and Income Inequality," Macroeconomic Dynamics, 20 (June 2016), 404-28.

Cortazar, Rene, "Unemployment Insurance Systems for Latin America," in Labor Market Policies in Canada and Latin America: Challenges of the New Millennium, ed. by Albert Berry, Springer (New York: 2001), 97-107.

Dabla-Norris, Era, Jim Brumby, Annette Kyobe, Zac Mills, and Chris Papageorgiou, "Investing in Public Investment: An Index of Public Investment Efficiency," Journal of Economic Growth, 17 (September 2012), 235-66.

De la Croix, David, and Philippe Michel, A Theory of Economic Growth: Dynamics and Policy in Overlapping Generations, Cambridge University Press (October 2002).

Dinopoulos, Elias, and Paul S. Segerstrom, "A Schumpeterian Model of Protection and Relative Wages," American Economic Review, 89 (September 1999), 450-72.

Duval, Romain, and Davide Furceri, "The Effects of Labor and Product Market Reforms: The Role of Macroeconomic Conditions and Policies," IMF Economic Review, 66 (March 2018), 31-69.

Ferreira, Pedro C., Samuel D. Pessoa, and Fernando A. Veloso, "On the Evolution of Total Factor Productivity in Latin America," Economic Inquiry, 51 (January 2013), 16-30.

Ferrer, Ana, and W. Craig Riddell, "Unemployment Insurance Savings Accounts in Latin America: Overview and Assessment," Social Protection Discussion Paper No. 910, World Bank (June 2009).

Ferreyra, Maria M., Ciro Avitabile, Javier Botero Álvarez, Francisco Haimovich Paz, and Sergio Urzúa, At A Crossroads: Higher Education in Latin America and the Caribbean, World Bank Publications (Washington DC: 2017).

Flynn, James R., What is Intelligence?, Cambridge University Press (New York: 2007).

Gancia, Gino, and Fabrizio Zilibotti, "Horizontal Innovation in the Theory of Growth and Development," in Handbook of Economic Growth, Vol. 1A, ed. by Philippe Aghion and Steven Durlauf, North Holland (Amsterdam: 2005).

Gandelman, Néstor, "A Comparison of Saving Rates: Micro Evidence from Seventeen Latin American and Caribbean Countries," Working Paper No. 602, Inter-American Development Bank (July 2015). 
Heer, Burkhard, and Albrecht Morgenstern, "The Labor Market Effects of Indexing Unemployment Benefits to Previous Earnings," Public Finance Review, 33 (May 2005), 385-402. Inter-American Development Bank, Good Jobs Wanted: Labor Markets in Latin America, IDB publications (Washington DC: 2004).

International Labour Organization, Labour Overview of Latin America and the Caribbean, ILO Publications (Geneva: 2017).

International Monetary Fund, "Time for a Supply-Side Boost? The Macroeconomic Effects of Labor and Product Market Reforms in Advanced Economies," Chapter 3 in World Economic Outlook, IMF Publications (Washington DC: 2016).

Jones, Charles I., "Growth and Ideas," in Handbook of Economic Growth, ed. by Philippe Aghion and Steven Durlauf, Elsevier, Vol. 1B (Amsterdam: 2005), 1063-111.

Leuven, Edwin, and Hessel Oosterbeek, "Overeducation and Mismatch in the Labor Market," in Handbook of the Economics of Education, ed. by Eric A. Hanushek, Stephen J. Machin, and Ludger Woessmann, Vol. 4, North Holland (Amsterdam: 2011).

Loayza, Norman, Pablo Fajnzylber, and César Calderón, Economic Growth in Latin America and the Caribbean: Stylized Facts, Explanations, and Forecasts, World Bank (March 2005).

Lora, Eduardo, and Deisy J. Fajardo, "Employment and Taxes in Latin America: An Empirical Study of the Effects of Payroll, Corporate Income and Value-added Taxes on Labor Outcomes," Working Paper No. 334, Inter-American Development Bank (September 2012).

LSE Growth Commission, Investing for Prosperity: Skills, Infrastructure and Innovation, London School of Economics (London: 2013).

Marioni, Larissa da Silva, "Overeducation in the Labour Market: Evidence from Brazil," unpublished, University of Southampton (March 2018).

Meckl, Jurgen, "Accumulation of Technological Knowledge, Wage Differentials, and Unemployment," Journal of Macroeconomics, 26 (March 2004), 65-82.

Millán, Ana, José María Millán, Concepción Román, and André van Stel, "How does Employment Protection Legislation Influence Hiring and Firing Decisions by the Smallest Firms?," Economics Letters, 121 (December 2013), 444-48.

Montuenga, Víctor, Inmaculada García, and Melchor Fernández, "Wage Flexibility: Evidence from Five EU Countries based on the Wage Curve," Economic Letters, 78 (February 2003), 169-74.

Mora, Jhon J., "Sobre-Educación en el Mercado Laboral Colombiano," Revista de Economía Institucional, 10 (July 2008), 293-309.

Neumark, David, and William Wascher, "Minimum Wages and Employment: A Review of Evidence from the New Minimum Wage Research," Working Paper No. 12663, National Bureau of Economic Research (November 2006).

Parello, Carmelo P., "Labor Market Rigidity and Productivity Growth in a Model of InnovationDriven Growth," Economic Modelling, 28 (May 2011), 1058-67.

Romer, Paul M., "Endogenous Technological Change," Journal of Political Economy (October 1990), s71-102. 
Serebrisky, Tomás, Ancor Suárez-Alemán, Diego Margot, and Maria Cecilia Ramirez, Financing Infrastructure in Latin America and the Caribbean: How, how much and by whom?, Inter-American Development Bank (Washington DC: 2015).

Tafunell, Xavier, and Cristian Ducoing, "Non-Residential Capital Stock in Latin America, 1875-2008: New Estimates and International Comparisons," Australian Economic History Review, 56 (March 2016), 46-69.

Varga, Janos, Werner Roeger, and Jan in't Veld, "Growth Effects of Structural Reforms in Southern Europe: The Case of Greece, Italy, Spain and Portugal," Empirica, 41 (May 2014), 323-63.

World Bank, Jobs, World Bank publications (Washington DC: 2012a).

- Golden Growth: Restoring the Lustre of the European Economic Model, World Bank publications (Washington DC: 2012b).

Yamada, Gustavo, "The Boom in University Graduates and the Risk of Underemployment," IZA World of Labor No. 165 (July 2015).

Zagler, Martin, "Economic Growth, Structural Change, and Search Unemployment," Journal of Economics, 96 (January 2009), 63-78.

—, "Endogenous Growth, Efficiency Wages, and Persistent Unemployment, Review of Economics and Finance, 1 (March 2011), 34-42. 
Table 1

Parameter Values: Benchmark Case

\begin{tabular}{|c|c|c|}
\hline Parameter & Description & Value \\
\hline \multicolumn{3}{|l|}{ Households } \\
\hline$\rho$ & Intergenerational discount rate & 0.375 \\
\hline$\sigma$ & Household savings rate & 0.138 \\
\hline$\chi$ & Productivity parameter (efficiency of training) & 0.5 \\
\hline$\mu$ & Advanced education cost & 0.12 \\
\hline$\varepsilon$ & Time allocated to schooling activity & 0.123 \\
\hline \multicolumn{3}{|l|}{ Final good } \\
\hline$\omega$ & Elasticity wrt public-private capital ratio & 0.24 \\
\hline$\beta^{S}$ & Elasticity wrt specialized workers & 0.35 \\
\hline$\beta^{U}$ & Elasticity wrt untrained workers & 0.2 \\
\hline$\alpha$ & Elasticity wrt private capital & 0.35 \\
\hline$\gamma$ & Elasticity wrt intermediate input & 0.1 \\
\hline \multicolumn{3}{|c|}{ Intermediate goods } \\
\hline$\eta$ & Substitution parameter, intermediate goods & 0.25 \\
\hline \multicolumn{3}{|c|}{ Innovation sector } \\
\hline$\phi_{1}^{R}$ & Elasticity wrt public infrastructure & 0.300 \\
\hline$\pi$ & Probability of being caught shirking & 0.048 \\
\hline$\delta_{R}$ & Elasticity wrt wage for innovation & 0.9 \\
\hline$\lambda$ & Elasticity of production wrt labor input & 0.6 \\
\hline$\psi$ & Elasticity of effort wrt relative wages & 0.43 \\
\hline \multicolumn{3}{|l|}{ Government } \\
\hline$\tau$ & Tax rate on total wages & 0.123 \\
\hline$v_{I}$ & Share of spending on infrastructure & 0.069 \\
\hline$\varphi$ & Efficiency parameter, public investment & 0.4 \\
\hline \multicolumn{3}{|l|}{ Labor market } \\
\hline$\kappa^{S}$ & Specialized labor, unemp. benefit indexation & 0.4 \\
\hline$\kappa^{U}$ & Untrained labor, unemp. benefit indexation & 0.4 \\
\hline$\xi^{U}$ & Relative weight, untrained workers & 0.08 \\
\hline$\xi^{S Y}$ & Relative weight, specialized workers & 0.08 \\
\hline$w_{0}^{U}$ & Minimum wage indexation, untrained workers & 0.546 \\
\hline$w_{0}^{S Y}$ & Minimum wage indexation, specialized workers & 0.699 \\
\hline$\varkappa^{U}$ & Elasticity wrt unemployment, untrained wage & 0.12 \\
\hline$\varkappa^{S}$ & Elasticity wrt unemployment, specialized wage & 0.12 \\
\hline
\end{tabular}


Table 2

Initial Steady-State Values of Key Variables

\begin{tabular}{clc}
\hline \hline Variable & \multicolumn{1}{c}{ Description } & Value \\
\hline \hline$\theta^{U}$ & Share of untrained workers in population & 0.795 \\
$\theta^{S}$ & Share of effective specialized workers in population & 0.184 \\
$\theta^{S R}$ & Share of effective specialized workers in innovation sector & 0.004 \\
$\theta^{S Y}$ & Share of effective specialized workers in final good sector & 0.109 \\
$\theta^{U Y}$ & Share of untrained workers in final good sector & 0.708 \\
$\theta^{U L}$ & Untrained unemployment rate & 0.087 \\
$\theta^{S L}$ & Specialized unemployment rate & 0.071 \\
$\left.\theta^{R}-\theta^{S R}\right) / \theta^{S Y}$ & Index of misallocation of talent & 0.392 \\
$\zeta^{S L}$ & Probability of specialized workers getting unemployed & 0.385 \\
$\zeta^{S Y}$ & Prob. of specialized workers employed in final good sector & 0.593 \\
$\zeta^{S R}$ & Prob. of specialized workers employed in innovation sector & 0.022 \\
$\zeta^{U L}$ & Prob. of untrained workers getting unemployed & 0.110 \\
$\zeta^{U Y}$ & Prob. of untrained workers getting employed & 0.890 \\
$S^{S}$ & Firms' payroll contribution rate & 0.052 \\
$w^{U} / w_{\text {weighted }}$ & Relative wage ratio & 0.750 \\
$k^{G}$ & Public-private capital ratio & 0.147 \\
$Y / K^{P}$ & Final output-private capital ratio & 0.429 \\
$m$ & Stock of innovation-private capital ratio & 0.100 \\
\hline \hline
\end{tabular}


Table 3

Summary of Benchmark Individual Policy Experiments* [Absolute deviations from baseline]

\begin{tabular}{|c|c|c|c|c|c|c|c|}
\hline \multirow{3}{*}{ Share of untrained workers } & \multirow{2}{*}{$\begin{array}{c}\text { Steady-state } \\
\text { value }\end{array}$} & \multicolumn{2}{|c|}{$\begin{array}{c}\text { Reduction in Base Minimum } \\
\text { Wage }\end{array}$} & \multicolumn{2}{|c|}{$\begin{array}{l}\text { Reduction in Untrained } \\
\text { Workers' UB Indexation }\end{array}$} & \multicolumn{2}{|c|}{$\begin{array}{l}\text { Reduction in Specialized } \\
\text { Workers' UB Indexation }\end{array}$} \\
\hline & & Impact & Steady-state & Impact & Steady-state & Impact & Steady-state \\
\hline & 0.795 & 0.000 & -0.001 & 0.000 & -0.001 & 0.001 & 0.002 \\
\hline Effective share of specialized workers & 0.184 & 0.000 & 0.001 & 0.000 & 0.001 & -0.001 & -0.002 \\
\hline Share of specialized workers in innovation & 0.004 & 0.000 & 0.000 & 0.000 & 0.000 & 0.000 & 0.000 \\
\hline Expected wage premium & 0.333 & 0.002 & 0.008 & 0.006 & 0.004 & -0.022 & -0.016 \\
\hline Index of misallocation of talent & 0.392 & -0.001 & -0.004 & -0.001 & -0.002 & -0.001 & 0.000 \\
\hline Untrained unemployment rate & 0.087 & -0.009 & -0.020 & 0.000 & -0.002 & 0.000 & 0.000 \\
\hline Specialized unemployment rate & 0.071 & 0.000 & 0.000 & 0.000 & 0.000 & -0.001 & -0.002 \\
\hline Total unemployment rate & 0.079 & -0.007 & -0.015 & 0.000 & -0.001 & 0.000 & 0.000 \\
\hline Payroll contribution rate & 0.052 & -0.002 & -0.007 & -0.002 & -0.004 & -0.002 & -0.003 \\
\hline Growth rate of final output & 0.039 & 0.003 & 0.000 & -0.002 & 0.000 & -0.006 & 0.000 \\
\hline \multirow[t]{3}{*}{ Social welfare } & 1.000 & & 0.004 & & -0.076 & & -0.223 \\
\hline & \multirow{2}{*}{$\begin{array}{c}\text { Steady-state } \\
\text { value }\end{array}$} & \multicolumn{2}{|c|}{$\begin{array}{l}\text { Reduction in both UB } \\
\text { Indexation Parameters }\end{array}$} & \multicolumn{2}{|c|}{$\begin{array}{c}\text { Reduction in Untrained } \\
\text { Workers' Union Mark-up }\end{array}$} & \multicolumn{2}{|c|}{$\begin{array}{l}\text { Reduction in Specialized } \\
\text { Workers' Union Mark-up }\end{array}$} \\
\hline & & Impact & Steady-state & Impact & Steady-state & Impact & Steady-state \\
\hline Share of untrained workers & 0.795 & 0.001 & 0.002 & 0.000 & -0.001 & 0.000 & 0.001 \\
\hline Effective share of specialized workers & 0.184 & -0.001 & -0.001 & 0.000 & 0.001 & 0.000 & -0.001 \\
\hline Share of specialized workers in innovation & 0.004 & 0.000 & 0.000 & 0.000 & 0.000 & 0.000 & 0.000 \\
\hline Expected wage premium & 0.333 & -0.016 & -0.012 & 0.002 & 0.006 & -0.011 & -0.008 \\
\hline Index of misallocation of talent & 0.392 & -0.002 & -0.002 & -0.001 & -0.003 & -0.012 & -0.012 \\
\hline Untrained unemployment rate & 0.087 & 0.000 & -0.002 & -0.006 & -0.015 & 0.000 & 0.000 \\
\hline Specialized unemployment rate & 0.071 & -0.001 & -0.002 & 0.000 & 0.000 & -0.004 & -0.004 \\
\hline Total unemployment rate & 0.079 & 0.000 & -0.001 & -0.005 & -0.011 & -0.001 & -0.001 \\
\hline Payroll contribution rate & 0.052 & -0.004 & -0.007 & -0.001 & -0.005 & -0.001 & -0.002 \\
\hline Growth rate of final output & 0.039 & -0.008 & 0.000 & 0.002 & 0.000 & 0.015 & 0.000 \\
\hline \multirow[t]{3}{*}{ Social welfare } & 1.000 & & -0.280 & & 0.003 & & -0.026 \\
\hline & \multirow{2}{*}{$\begin{array}{c}\text { Steady-state } \\
\text { value }\end{array}$} & \multicolumn{2}{|c|}{$\begin{array}{l}\text { Advanced Education } \\
\text { Cost Cut }\end{array}$} & \multicolumn{2}{|c|}{$\begin{array}{c}\text { Increase in Public } \\
\text { Infrastructure Investment }\end{array}$} & & \\
\hline & & Impact & Steady-state & Impact & Steady-state & & \\
\hline Share of untrained workers & 0.795 & -0.020 & -0.050 & 0.000 & 0.000 & & \\
\hline Effective share of specialized workers & 0.184 & 0.016 & 0.038 & 0.000 & 0.000 & & \\
\hline Share of specialized workers in innovation & 0.004 & 0.001 & 0.002 & 0.001 & 0.001 & & \\
\hline Expected wage premium & 0.333 & -0.088 & -0.182 & 0.003 & 0.002 & & \\
\hline Index of misallocation of talent & 0.392 & -0.014 & -0.031 & -0.005 & -0.006 & & \\
\hline Untrained unemployment rate & 0.087 & -0.004 & -0.023 & 0.000 & 0.000 & & \\
\hline Specialized unemployment rate & 0.071 & 0.013 & 0.032 & 0.000 & 0.000 & & \\
\hline Total unemployment rate & 0.079 & -0.001 & -0.009 & 0.000 & 0.000 & & \\
\hline Payroll contribution rate & 0.052 & 0.002 & 0.003 & 0.000 & 0.000 & & \\
\hline Growth rate of final output & 0.039 & 0.004 & 0.002 & 0.050 & 0.001 & & \\
\hline Social welfare & 1.000 & & 0.058 & & -0.002 & & \\
\hline
\end{tabular}

*/ The respective individual policy shocks are: Reduction in $\mathrm{w}_{U_{0}}$ by 5 percent; $\mathrm{k}^{u}$ reduced by 10 percent;

$\mathrm{K}^{\mathrm{S}}$ reduced by 10 percent; both $\mathrm{K}^{U}$ and $\mathrm{K}^{\mathrm{S}}$ cut by 10 percent; $\xi^{U}$ reduced by 37.5 percent; $\xi^{\mathrm{SY}}$ reduced by 37.5 percent;

a decrease in advanced education cost by 5 percent;

and an increase in share of public infrastructure investment by 20 percent.

Source: Authors' calculations. 
Table 4

Summary of Benchmark Composite Reform Programs*

[Absolute deviations from baseline]

\begin{tabular}{|c|c|c|c|c|c|c|c|}
\hline & \multirow{2}{*}{$\begin{array}{c}\text { Steady-state } \\
\text { value }\end{array}$} & \multicolumn{2}{|c|}{ Program A } & \multicolumn{2}{|c|}{ Program B } & \multicolumn{2}{|c|}{ Program C } \\
\hline & & Impact & Steady-state & Impact & Steady-state & Impact & Steady-state \\
\hline Share of untrained workers & 0.795 & -0.001 & $-0.002 \mid$ & -0.021 & -0.049 & -0.021 & -0.049 \\
\hline Effective share of specialized workers & 0.184 & 0.001 & 0.002 & 0.016 & 0.038 & 0.016 & 0.038 \\
\hline Share of specialized workers in innovation & 0.004 & 0.000 & $0.000 !$ & 0.001 & $0.002 !$ & 0.001 & 0.003 \\
\hline Expected wage premium & 0.333 & -0.005 & 0.010 & -0.072 & -0.158 & -0.069 & -0.156 \\
\hline Index of misallocation of talent & 0.392 & -0.004 & -0.010 & -0.026 & -0.048 & -0.032 & -0.055 \\
\hline Untrained unemployment rate & 0.087 & -0.022 & -0.049 & -0.026 & -0.060 & -0.026 & -0.060 \\
\hline Specialized unemployment rate & 0.071 & 0.000 & -0.001 & 0.010 & $0.026 !$ & 0.009 & 0.026 \\
\hline Total unemployment rate & 0.079 & -0.017 & $-0.037 !$ & -0.017 & $-0.037 !$ & -0.018 & -0.037 \\
\hline Payroll contribution rate & 0.052 & -0.007 & -0.020 & -0.006 & -0.015 & -0.006 & -0.016 \\
\hline Growth rate of final output & 0.039 & 0.003 & 0.000 & 0.007 & 0.002 & 0.058 & 0.003 \\
\hline Social welfare & 1.000 & & -0.168 & & $-0.120 \mid$ & & -0.121 \\
\hline
\end{tabular}

*/ Program A includes a decrease in $\mathrm{K}^{\mathrm{s}}$ by 6.25 percent; a decrease in $\mathrm{K}^{\mathrm{u}}$ by 6.25 percent; a decrease in $\mathrm{w}_{\mathrm{Uo}}$ by 10 percent;

and a reduction in untrained union mark-up by 37.5 percent;

Program B includes a decrease in $\mu$ by 5 percent; an increase in advanced education period by 22 percent; a decrease in $\mathrm{k}^{\mathrm{J}}$ by 6.25 percent;

a decrease in $\mathrm{K}^{\mathrm{U}}$ by 6.25 percent; a decrease in $\mathrm{w}_{\mathrm{U}_{0}}$ by 10 percent; and a reduction in untrained union mark-up by 37.5 percent;

Program $C$ adds an increase in public infrastructure investment by 20 percent to Program $B$.

Source: Authors' calculations. 


\section{Figure 1}

\section{Production Structure and the Labor Market}

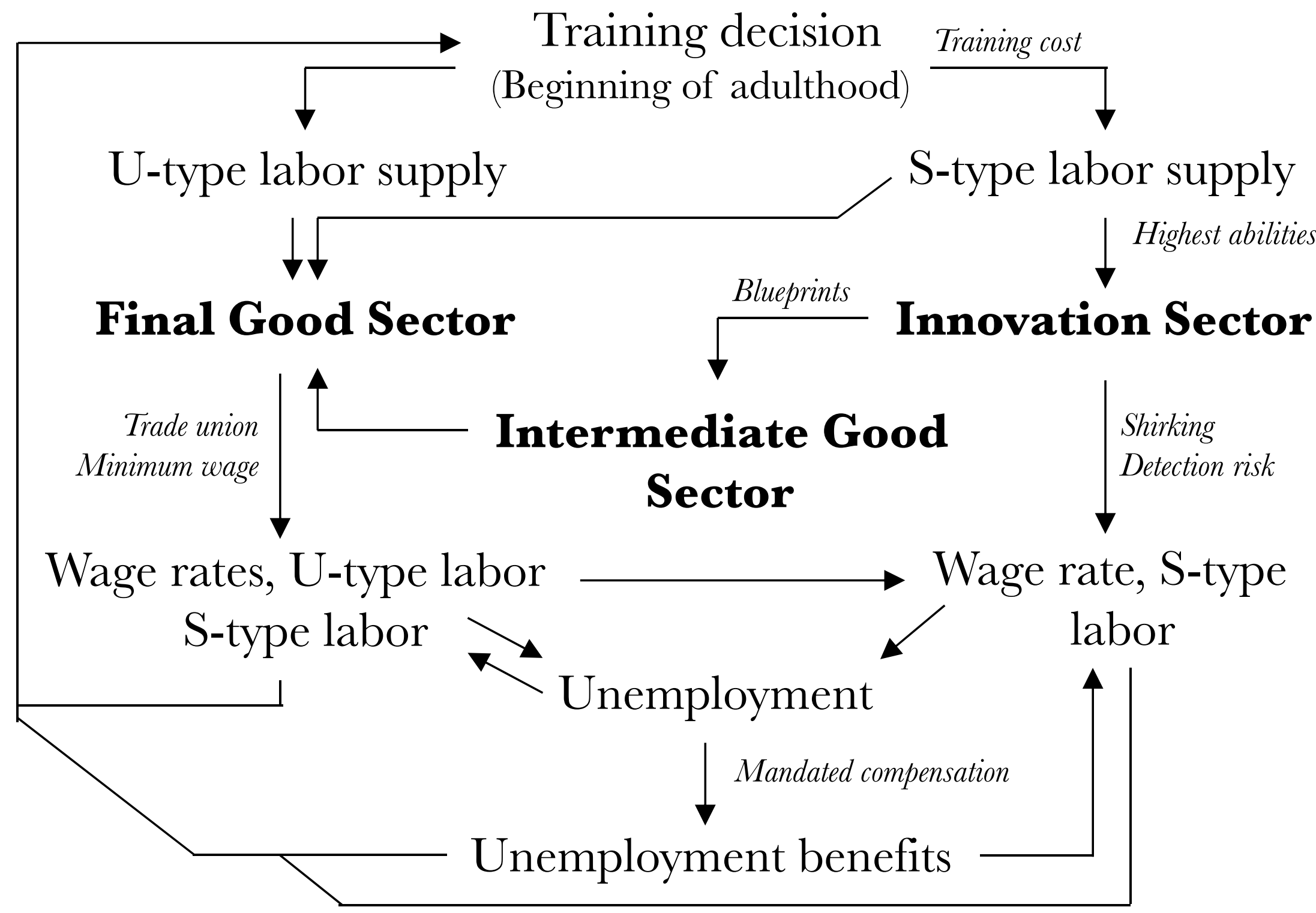


Figure 2

Individual and Composite Experiments

(Absolute deviations from baseline)

Impact effects

Total Unemployment Rate

Minimum wage cut

Untrained UB cut

Specialized UB cut

Untrained mark-up cut

Specialized mark-up cut

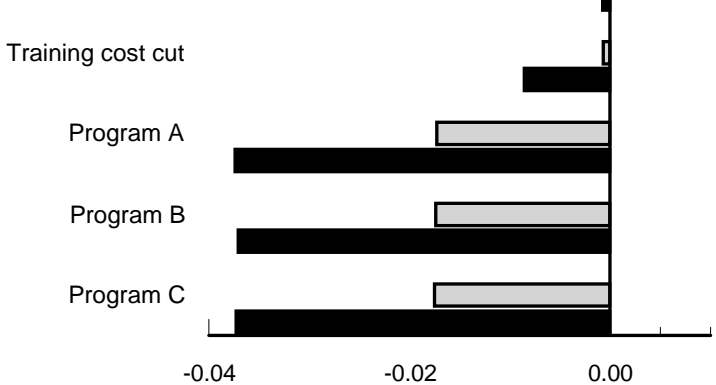

Index of Misallocation of Talent

Minimum wage cut

Untrained UB cut

Specialized UB cut

Untrained mark-up cut

Specialized mark-up cut

Training cost cut

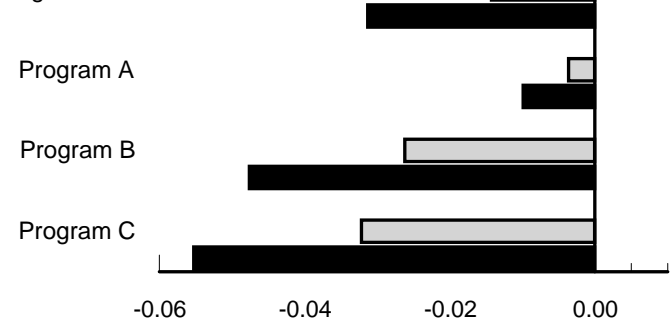

Steady-state effects

Final Output Growth Rate

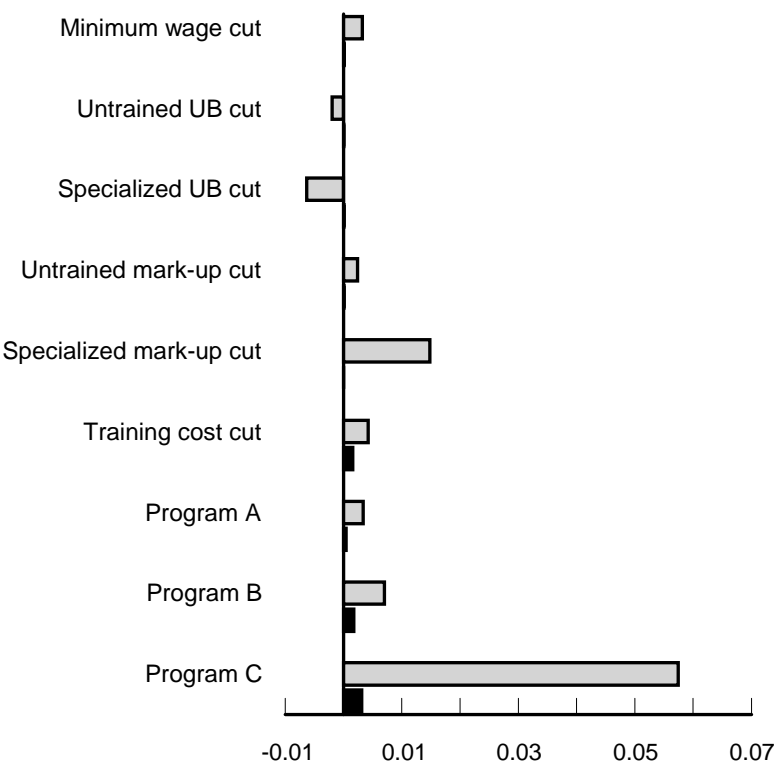

Social Welfare

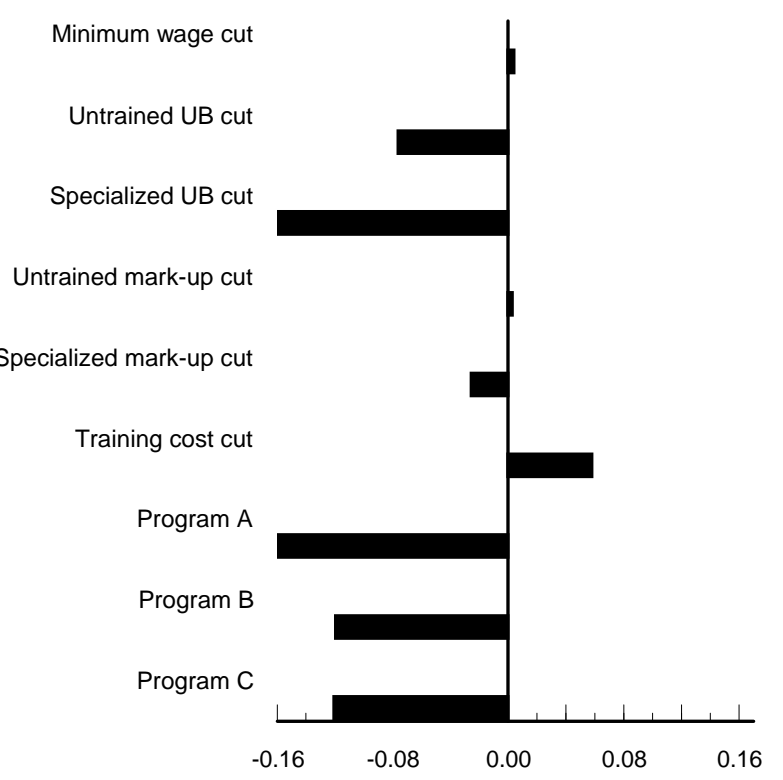

Source: Authors' calculation. 